\title{
From the gut to the peripheral tissues: the multiple effects of butyrate
}

\author{
P. Guilloteau ${ }^{1}$, L. Martin ${ }^{2,3}$, V. Eeckhaut ${ }^{4}$, R. Ducatelle ${ }^{4}$, R. Zabielski $^{5}$ and F. Van Immerseel ${ }^{4}$ \\ ${ }^{1}$ INRA, U1079, Unité Mixte de Recherche - Système Elevage, Nutrition Animale et Humaine (UMR SENAH), \\ Domaine de la Prise, 35590 Saint-Gilles, France \\ ${ }^{2}$ ONIRIS, UPSP Nutrition \& Endocrinologie, Nantes F-44307, France \\ ${ }^{3}$ Université de Nantes, Angers, Le Mans, France \\ ${ }^{4}$ Department of Pathology, Bacteriology and Avian Diseases, Faculty of Veterinary Medicine, Ghent University, \\ Ghent, Belgium \\ ${ }^{5}$ Department of Physiological Sciences, Faculty of Veterinary Medicine, Warsaw University of Life Sciences, Warsaw, Poland
}

\begin{abstract}
Butyrate is a natural substance present in biological liquids and tissues. The present paper aims to give an update on the biological role of butyrate in mammals, when it is naturally produced by the gastrointestinal microbiota or orally ingested as a feed additive. Recent data concerning butyrate production delivery as well as absorption by the colonocytes are reported. Butyrate cannot be detected in the peripheral blood, which indicates fast metabolism in the gut wall and/or in the liver. In physiological conditions, the increase in performance in animals could be explained by the increased nutrient digestibility, the stimulation of the digestive enzyme secretions, a modification of intestinal luminal microbiota and an improvement of the epithelial integrity and defence systems. In the digestive tract, butyrate can act directly (upper gastrointestinal tract or hindgut) or indirectly (small intestine) on tissue development and repair. Direct trophic effects have been demonstrated mainly by cell proliferation studies, indicating a faster renewal of necrotic areas. Indirect actions of butyrate are believed to involve the hormono-neuro-immuno system. Butyrate has also been implicated in down-regulation of bacteria virulence, both by direct effects on virulence gene expression and by acting on cell proliferation of the host cells. In animal production, butyrate is a helpful feed additive, especially when ingested soon after birth, as it enhances performance and controls gut health disorders caused by bacterial pathogens. Such effects could be considered for new applications in human nutrition.
\end{abstract}

\section{Gastrointestinal microbial ecosystem: Feed additives: Biological role of butyrate: Trophic} effects: Hormono-neuro-immuno system: Animal and human nutrition

\section{Introduction}

The SCFA constitute a group of molecules that contain from one to seven carbon atoms and which exist as straightor branched-chain compounds. They mainly originate from the intestinal bacterial fermentation of plant materials such as celluloses, fibres, starches and sugars for which mammals lack the necessary enzymes to split these compounds. Among the SCFA, acetic, propionic and butyric acid are the predominant forms. Because SCFA are weak acids with a $\mathrm{p} K$ of $\leq 4.8$ and the $\mathrm{pH}$ of the gastrointestinal (GI) tract (GIT) fermentation chambers is nearly neutral, $90-99 \%$ of the SCFA are present in the GIT as anions rather than as free acids $^{(1)}$. SCFA have several beneficial effects for animals. As an example, acetic and propionic acids, due to their physical and chemical properties, are used as acidifiers in pig diets in order to help overcome problems in the postweaning lag period. Moreover, dietary acidification is known to be beneficial for the performance of fattening animals $^{(1,2)}$. For ruminants and herbivorous animals, SCFA constitute the major substrates for energy production. Evidence also indicates that there is considerable fermentation in the caecum and colon of both human and nonherbivorous animals.

Among the SCFA, butyric acid has received particular attention. It is a natural substance present in the GIT, in milk as well as in the sweat and faeces of most mammals. Butyric acid is available as the $\mathrm{Na}, \mathrm{K}, \mathrm{Mg}$ or Ca salt. The advantage of salts over free acids is that they are generally odourless

\footnotetext{
Abbreviations: GI, gastrointestinal; GIT, gastrointestinal tract; GLP, glucagon-like peptide; GPR, G protein-coupled receptor; HSP, heatshock protein; MCT, monocarboxylate transporter; RS, resistant starch; SMCT, Na-coupled monocarboxylate transporter.

* Corresponding author: Dr P. Guilloteau, fax + 332234850 80, email Paul.Guilloteau@rennes.inra.fr, paul.guilloteau@gmail.com
} 
and easier to handle in the feed manufacturing process owing to their solid and less volatile form. For the purpose of the present review, the term 'butyrate' is used interchangeably for the acid, the salt and the anion forms. In the GIT, butyrate is naturally present in high concentration in the lumen of the large intestine. It is preferentially taken up by the colonic epithelium where it is actively metabolised to produce energy ${ }^{(3,4)}$. Much attention has been devoted to the anticancerous properties of butyrate in human nutrition despite numerous papers suggesting its role as a growth factor. The effects of butyrate, however, depend on the experimental model (in vivo, in vitro), the state of the cells (normal or cancerous) ${ }^{(5)}$, the degree of inflammation ${ }^{(6)}$ and the doses used ${ }^{(7)}$.

In addition to the recognised effects on intestinal metabolism, butyrate shows indirect effects that contribute to the general metabolism of animals. In all tissues butyrate is a natural component of cellular metabolism. It may also act as a growth promoter when added to diets at low doses $(0 \cdot 1-0.5 \mathrm{~g} / \mathrm{kg})^{(8)}$.

The purpose of the present paper is to give an overview of the properties of butyrate either originating from bacterial intestinal fermentation or added to the rations of animals. In addition to the recognised effects on intestinal metabolism, butyrate shows indirect effects that contribute to the general metabolism of animals.

\section{Production and delivery of butyrate in the gut}

\section{Butyrate production patterns in the gut at birth and during development}

In utero, the intestine of the mammalian fetus is sterile. At the time of delivery, the intestinal microbiota are acquired by swallowing maternal anal or vaginal organisms ${ }^{(9)}$. In poultry, hatching through the eggshell has a similar effect. The effect of the first inoculum may be lifelong, directing the development of the immune system and the normal intestinal microbiota. The bacterial composition of the inoculum received at birth, the structure of the host's intestinal epithelium and the diet all affect the density and composition of the microbiota ${ }^{(10)}$. These microbiota, particularly in the large intestine, have a fundamental role in supplying energy to the host through anaerobic fermentative processes producing $\mathrm{SCFA}^{(11)}$. Another source of SCFA in general and butyrate in particular is the milk. Butyric acid is a natural component of mammalian milk, except for human and sows' milk where only traces can be found. In cows' milk butyrate concentration is about $0.16 \mathrm{~g} / \mathrm{l}^{(12)}$, which seems to be insufficient to cover the energy needs of the GI epithelium in the newborn calf but it may be enough to stimulate GI development together with milk-borne hormones and growth factors such as insulin, leptin, glucagon-like peptide (GLP)-2, insulin-like growth factors, epithelial growth factor and many others ${ }^{(13)}$. Another source of butyrate in suckling neonates is the hydrolysis of milk lipids by salivary and gastric lipases. This source of butyrate is difficult to estimate but it may be utilised in the upper GIT. In newborn rats, very high levels of butyrate $\beta$-oxidation are detected in colonic epithelial cells. The high oxidation levels may be explained by the fact that the animal is geared to use luminal substrates (high-fat milk diet) with maximum efficiency ${ }^{(14)}$. The stools of normal full-term infants contain less than $100 \mathrm{mM}-S C F A^{(15)}$, with acetate being the major and butyrate the minor acid found in the faeces of formula fed-babies, while virtually no butyrate is found in the faeces of breast-fed infants ${ }^{(16)}$. In premature infants deficient in intestinal lactase, high concentrations of SCFA are produced due to carbohydrate malabsorption, bacterial overgrowth and poor intestinal motility and can significantly lower the $\mathrm{pH}$ of the intestinal luminal contents. When specific pathogens, such as Clostridium difficile, proliferate in this environment, they can cause necrotising enterocolitis ${ }^{(17)}$. In healthy infants, fermentation is lower than in adults and butyrate production is established at a slower rate than for acetate and propionate but, by 2 years, an adult SCFA profile has emerged ${ }^{(18)}$. Similar SCFA production patterns have been detected in animals. In broilers aged $1 \mathrm{~d}$, SCFA increased from undetectable levels to high concentrations in broilers aged $15 \mathrm{~d}$, and then stabilised ${ }^{(19)}$.

\section{Butyrate production in the gut of adult animals}

Large bowel fermentation: the main source of available butyrate. In ruminants, the resident microbiota components are essential, as they convert the feed components into nutrients that are readily available for the animal. In single-stomached animals, less microbial involvement is needed, as most nutrients in the diet are directly available to the host. Whilst bacteria affect the performance of the host by competing for dietary compounds, they also provide energy to the host through fermentation. Based on the location of fermentation, animals can be classified into forestomach fermenters and hindgut fermenters. Forestomach fermenters such as ruminants, camels, hippopotamuses and some monkeys have a fermentation chamber cranial to the acid-secreting part of the stomach. Rodents, horses, elephants and most omnivores and carnivores are hindgut and large intestine and/or caecum fermenters, with the GIT serving as a chamber for microbial action and SCFA production ${ }^{(1)}$. Elsden et al. ${ }^{(20)}$, 60 years ago, compared total SCFA concentration at different sites in the GIT of a number of herbivorous and omnivorous species and noticed the highest concentrations in the caecum, and a progressive decline along the colon. In mice and rats, a higher concentration of SCFA was reported in the caecum compared with the colon $^{(21)}$. While in ruminants the highest concentration of SCFA was found in the rumen, another peak was measured in the caecum and colon, indicating that even in forestomach fermenters considerable further digestion occurs in the large intestine $^{(1)}$. The intestine contains several different bacterial species. Saccharolytic bacteria, leading to linear SCFA, $\mathrm{CO}_{2}$ and $\mathrm{H}_{2}$, predominate in the proximal colon, while the majority of proteolytic bacteria, yielding branched SCFA, $\mathrm{CO}_{2}, \mathrm{CH}_{4}, \mathrm{H}_{2}$, phenols and amines, are mainly in the distal colon where fermentable carbohydrates are depleted on transit ${ }^{(22,23)}$.

Polysaccharides, oligosaccharides and disaccharides resistant to the action of hydrolytic enzymes in the upper GIT enter into the caeco-colon. Here, the carbohydrates are 
depolymerised to their constituent sugars by a wide range of bacterial cell-associated (Fig. 1) and secreted hydrolytic enzymes such as $\beta$-fructosidase, $\beta$-galactosidase, xylanase and other hydrolases, and are then fermented ${ }^{(24)}$. Energy is gained in the form of ATP by substrate-level phosphorylation during oxidative substrate breakdown via the fermentation process. The transfer of the resulting reducing equivalents into the metabolic intermediates leads to the formation of large amounts of reduced endproducts such as butyrate, which acts as a terminal electron acceptor in an environment limited in $\mathrm{O}_{2}$. There are two distinct pathways for the production of intracellular butyrate in bacteria. In the first pathway butyryl-CoA is converted to butyrate with the intermediate formation of butyryl phosphate by the enzymes phosphotransbutyrylase and butyrate kinase ${ }^{(25)}$. In the second pathway the enzyme butyryl-CoA:acetate $\mathrm{CoA}$ transferase is involved and transfers the CoA moiety from butyryl-CoA to external acetate, which leads to the formation of acetyl-CoA and butyrate. The CoA transferase route is shown to be more dominant in the human butyrateproducing microbiota ${ }^{(26)}$. In vitro data show that strains possessing the CoA transferase convert $75 \%$ of the supplied glucose into lactate when acetate is absent. In the presence of acetate, mainly butyrate is produced ${ }^{(27)}$.

Substrates used for bacterial fermentation with butyrate as endproduct. In the large intestine, the ubiquitous nutrient glucose is only of secondary importance. Enterocytes use both glutamine and glucose as the favoured metabolic fuels, while colonocytes preferentially use butyrate ${ }^{(4)}$. The rate and amount of butyrate produced along the colonic lumen depends on the microbiota composition, the chemical composition, the physical form and the amount of substrates available in the diet. Substrates can be indigestible or digestible carbohydrates and, additionally, sloughed cells, mucus and endogenous secretions may also provide some fermentable substances. Examples of indigestible carbohydrates are oligosaccharides (for example, raffinose, oligofructose, inulin) and NSP which can be soluble (for example, -glucans) or insoluble (for example, cellulose and hemicellulose). The former are highly fermentable and

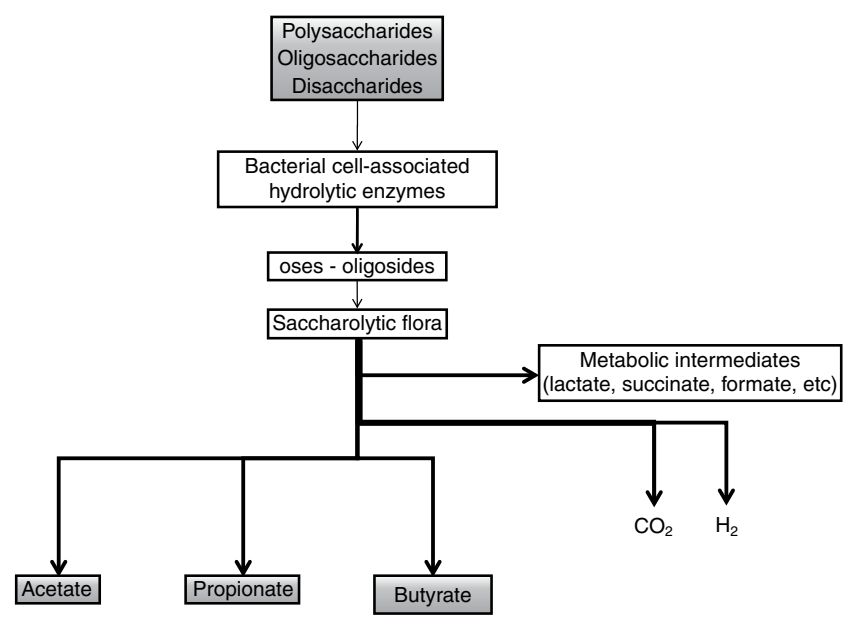

Fig. 1. Overview of butyrate production in the gut of adult animals. hence generate greater quantities of SCFA in the colon while the latter have a rather low fermentability but increase the faecal bulking and decrease the colonic transit time. The most important digestible carbohydrate is starch, known as resistant starch (RS; D-glucose units connected by $\alpha-1,4 / \alpha-1,6$ glucosidic bonds) when it has escaped digestion and/or absorption in the small intestine. RS can be subdivided into four types: physically trapped starch (in coarse grains), RS granules naturally rich in amylose (i.e. raw potato flour), retrograded starch (i.e. cooked and cooled potato) and chemically modified starch (i.e. processed foods) $^{(28)}$.

As a result of increasing concentrations of acidic fermentation products, the luminal $\mathrm{pH}$ in the proximal colon is lower. This $\mathrm{pH}$ seems to boost the formation of butyrate, as mildly acidic $\mathrm{pH}$ values allow butyrateproducing bacteria to compete against Gram-negative carbohydrate-utilising bacteria such as Bacteroides spp. ${ }^{(29)}$. An in vitro fermentation study, using faecal inoculum, showed that the population of butyrate producers, as well as the concentration of butyrate, was significantly higher at $\mathrm{pH} 5.5$ while Bacteroidetes dominated as the fermenter was at $\mathrm{pH}$ 6.5. Lowering the $\mathrm{pH}$ value further, for example, to $\mathrm{pH} 5 \cdot 2$, resulted in the loss of lactateutilising bacteria, such as Eubacterium hallii, leading to the accumulation of lactic acid ${ }^{(2)}$. Although all dietary fermentable carbohydrates reaching the hindgut have the potential to be converted to butyrate, not all are equally butyrogenic. In vitro ${ }^{(30)}$, animal ${ }^{(31)}$ and human ${ }^{(32)}$ studies have shown that RS fermentation generates relatively more butyrate than NSP fermentation. Butyrogenic substrates may affect the fermentative metabolism in individual bacteria, as more substrate leads to enhanced butyrate formation, which provides a route for the disposal of excess reducing equivalents (i.e. butyrate is used as a hydrogen sink). Butyrogenic substrates may also affect the microbial population by stimulating butyrate-producing species that are efficient primary degraders of these substrates ${ }^{(33)}$. Indirect stimulation of butyrate production occurs by metabolic cross-feeding. The first mechanism is via crossfeeding of oligosaccharide breakdown products released by active polysaccharide-metabolising bacteria. These breakdown products are then fermented by butyrate producers. This was demonstrated in in vitro cultures between bifidobacteria and butyrate-producing species ${ }^{(34)}$. The second mechanism is via cross-feeding of fermentation products such as lactate, ethanol and succinate. These compounds are intermediates in the global fermentation process in the microbiota and are detected in very low concentrations in healthy subjects. In vitro, the accumulation of lactate is prevented when human butyrate-producing strains such as Eubacterium hallii and Anaerostipes caccae are grown in co-culture with lactate-producing strains such as Bifidobacterium adolescentis ${ }^{(35)}$.

Scientific reports support the view that RS is the most powerful butyrogenic substrate ${ }^{(36)}$. Both in vitro as well as in vivo fermentation of RS generally results in butyrate production in the order of 20 to $28 \mathrm{~mol} \%$ compared with about 10 to $15 \mathrm{~mol} \%$ for $\mathrm{NSP}^{(37)}$. In rats fed RS-containing diets, there was a significant increase of the number of bifidobacteria and lactobacilli. Although these bacteria are 
predominantly acetate and lactate producers and not butyrate producers, butyrate production was significantly enhanced. Therefore it was accepted that the increased number of lactic acid bacteria induced a higher production of lactate that was efficiently converted to butyrate by lactic acid-utilising bacteria ${ }^{(38)}$. Due to the variable structure and complexity of starch, the exact starch type has a considerable impact ${ }^{(37)}$. Among RS, the retrograded RS (RS3) seems to be the most powerful butyrogenic substrate $^{(37)}$. The butyrogenic properties of RS3 is linked to the length of the 1,4- $\alpha$-D-glucans chain. Chain lengths with a degree of polymerisation of about 20-35 units of glucose are optimal for a high output of butyrogenic $\mathrm{RS}^{(39)}$. It is possible to increase the butyrate production from RS3 fermentation by an appropriate hydrothermal treatment. In a recent study, Jacobasch et al. (39) compared the physiological effects of three RS3 in rats: Novelose 330, annealing-Novelose and heat moisturetreated Novelose. In the caecum, proximal colon and distal colon treated with RS3, the digestive concentration of butyrate significantly increased and in the distal colon, heat moisture-treated Novelose yielded the highest butyrate concentration. This result is of great importance because a high butyrate concentration in the distal part of the colon is considered to be essential for colonocyte health and may have many implications in the prevention and the treatment of some chronic digestive diseases such as diverticulosis. The ability to produce butyrate from RS is also a dose-related effect and may vary greatly among individuals $^{(40)}$.

Oligofructose compounds are also associated with greater butyrate production. Although oligofructose is thought to be selectively fermented by bifidobacteria and, to a lesser extent, by lactobacilli, due to their production of $\beta$-fructosidase that cleaves the $\beta-(2-1)$ bonds present in oligofructose and inulin, stimulation of butyrate-producing bacteria is observed ${ }^{(41)}$.

Besides dietary fibres, other substrates using different mechanisms are known to increase butyrate concentration. An example is acarbose, an oligosaccharide that increases the amount of starch entering the colon by acting as an $\alpha$-glucosidase inhibitor ${ }^{(42)}$. Also, the kinetics of butyrate production varies widely between substrates. For example, fructo-oligosaccharides are known to be rapidly fermented, whereas RS is more slowly degraded and can reach the distal part of the colon ${ }^{(43,44)}$.

There is little information to explain why bacterial fermentation of specific carbohydrates, such as RS and oligofructose, selectively increases butyrate production, but it is assumed that interconversion reactions from primarily lactate and acetate are largely involved. In the rumen up to $60 \%$ of butyrate is synthesised directly from extracellular acetate through interconversion reactions ${ }^{(45)}$. Acetate and butyrate are interconvertible, but due to the net gain of ATP, the conversion of butyrate to acetate is more favourable for the microbial metabolism ${ }^{(46)}$.

Butyrate-producing microbiota. Culture-independent surveys of the adult human gut microbiota have revealed two bacterial phyla, the Bacteroidetes and the Firmicutes ${ }^{(47)}$, commonly dominating this ecosystem. This is also the case for the gut of at least sixty mammalian species ${ }^{(48)}$. The dominant groups found in the large intestines of human subjects ${ }^{(49)}$, pigs $^{(50)}$ and horses ${ }^{(51)}$ and in the rumen of cattle are the Cytophaga, Flavobacterium, Bacteroides (CFB) group of Gram-negative bacteria, and the Clostridium cluster XIVa (Clostridium coccoides) and cluster IV (Clostridium leptum) group of Gram-positive bacteria ${ }^{(10)}$. In poultry, relatives of Clostridium leptum and Clostridium coccoides groups dominate the caecum ${ }^{(52)}$. A high frequency of the Sporomusa group (Clostridium cluster IX), which includes major propionate producers, was reported while no numbers of the CFB group were detected in the avian caecum ${ }^{(53)}$. Sonnenburg et al. ${ }^{(54)}$ demonstrated that members of the Bacteroidetes phylum harbour a large set of genes which encode functions necessary to detect, bind, degrade and import carbohydrates encountered in the gut habitat - either from the diet or from host glycans associated with mucus and the surfaces of epithelial cells. The substrate breakdown products released by those primary degraders may be used by a myriad of other bacterial groups including the butyrate-producer group. The butyrate-producing bacteria cultured so far are strictly anaerobic firmicute bacteria, generally regarded as difficult to grow in vitro. The bacteria are Gram-positive, having a low mol\% guaninecytosine (G-C) content and are widely distributed across several clusters within the order Clostridiales. Those clostridial clusters (I-XIX) form a new nomenclature that rearranges the grouping of bacteria based on studies of the evolutionary relationships by $16 \mathrm{~S}$ rRNA sequencing ${ }^{(55)}$. The bulk of the butyrate-producers belong to cluster IV and cluster XIVa and include some potentially important butyrate producers related to Faecalibacterium prausnitzii, Eubacterium rectale and Roseburia species, respectively ${ }^{(56)}$. In humans, the butyrate-producing bacteria related to $F$. prausnitzii comprise $5-15 \%$ of the total microbiota $^{(49)}$ and $5-10 \%$ of the total microbiota species are related to Eubacterium rectale and Roseburia ${ }^{(57)}$. In recent studies of poultry, two butyrate producers were described: Butyricicoccus pullicaecorum ${ }^{(58)}$, related to F. prausnitzii, and A. butyraticus ${ }^{(59)}$, closely related to A. caccae, the lactate-utilising bacteria routinely detected in faecal samples from healthy individuals ${ }^{(10)}$. In the rumen of cattle and sheep, predominating butyrateproducing bacteria belong to cluster XIVa and are represented by Butyrivibrio fibrisolvens strains ${ }^{(60,61)}$. Butyrivibrio fibrisolvens is also present in the faecal flora of man, rabbits and horses ${ }^{(62)}$.

Depending on the environmental conditions, fermentative metabolism of butyrate producers can result in butyrate, formate, $\mathrm{H}_{2}, \mathrm{CO}_{2}$, while lactate and acetate can be either produced or consumed ${ }^{(56)}$. Butyrate producers are considered to play an important role in maintaining gut health mainly through the production of butyrate. Other traits beneficial for the hosts' health are their capacity to stabilise the luminal $\mathrm{pH}$ by consumption of lactate or the anti-inflammatory effect of some butyrate producers ${ }^{(63)}$. Given the importance of butyrate to colonic epithelial metabolism, it is reasonable to assume that butyrate-producing bacteria are well tolerated by the innate immune system ${ }^{(64)}$. 


\section{Absorption, transport and metabolism of butyrate \\ Absorption of butyrate, SCFA membrane receptor and transport proteins}

Earlier studies have demonstrated that SCFA are absorbed in both the small and large intestine by similar mechanisms ${ }^{(65,66)}$. More recent studies suggest the existence of species differences and different transporter isoforms expressed in enterocytes along the intestine ${ }^{(67)}$. On the apical membrane of the epithelial cell, distinct transport mechanisms have been reported, i.e. non-ionic diffusion and mechanisms involving $\mathrm{SCFA} / \mathrm{HCO}_{3}{ }^{-}$exchangers, monocarboxylate transporter (MCT) type $1^{(68,69)}$, and Na-coupled $\mathrm{MCT}^{(70)}$ (SMCT or SLC5A8/12). On the basolateral membrane, a carrier-mediated, $\mathrm{HCO}_{3}{ }^{-}$-gradient-dependent anion-butyrate exchange system (Fig. 2) is found ${ }^{(71)}$. The human intestine constitutes MCT3, MCT4 and MCT5 isoforms (the MCT6 expression was not found), with low expression of MCT3 in the ileum, and high expression of MCT4 and MCT5 found predominantly in distal colon ${ }^{(67)}$. In ruminant species, the SCFA-transporting mechanisms in the rumen epithelium are highly efficient, and lead to absorption of nearly all volatile fatty acids. Anion competition experiments in the washed ovine reticulorumen segments revealed that SCFA can be transported by both bicarbonate-dependent and bicarbonate-independent protein-coupled mechanisms ${ }^{(72)}$. The latter was not coupled with MCT.
MCT are involved in butyrate transport in pig and human colonic luminal membrane. Ritzhaupt et al. ${ }^{(68,69)}$ demonstrated that butyrate uptake is via a pH-activated, electroneutral anion exchange system. The optimal $\mathrm{pH}$ for the activity of the colonic butyrate transporter seems to be 5.5. Butyrate transport with MCT is saturable, coupled with $\mathrm{H}^{+}$and inhibited by several monocarboxylates such as acetate, propionate, pyruvate, L-lactate and $\alpha$-ketobutyrate. More recently, a second class of MCT was identified ${ }^{(70)}$, named SMCT. Two proteins have been cloned: SLC5A8 or SMCT1 and SLC5A12 or SMCT2 ${ }^{\text {(73) }}$. Conversely to MCT, SMCT transport mechanism involves $\mathrm{Na}^{+}$uptake by the transport cycle and also uses nicotinate and ketone bodies as substrates. In the colon, Li et al. ${ }^{(17)}$ showed that SLC5A12 (or SMCT2) functions as a tumour suppressor. Ganapathy et $a l .^{(70)}$ demonstrated that a non-malignant colon cell line expresses the transporter contrary to malignant cells. So, exposure of non-malignant cells to butyrate does not induce apoptosis. However, when SLC5A12 (SMCT2) is ectopically expressed in malignant cells and when butyrate is added in the culture medium, cells undergo massive apoptosis. In the normal colon, SLC5A8 is claimed to have less importance in butyrate transport than $\mathrm{MCT}^{(74)}$ but it plays a key function in intestinal lactate absorption. In humans, SLC5A8 is considered a tumour suppressor ${ }^{(75)}$. During the transformation of non-malignant cells into malignant ones, expression of SLC5A8 is silenced perhaps to avoid butyrate inhibition

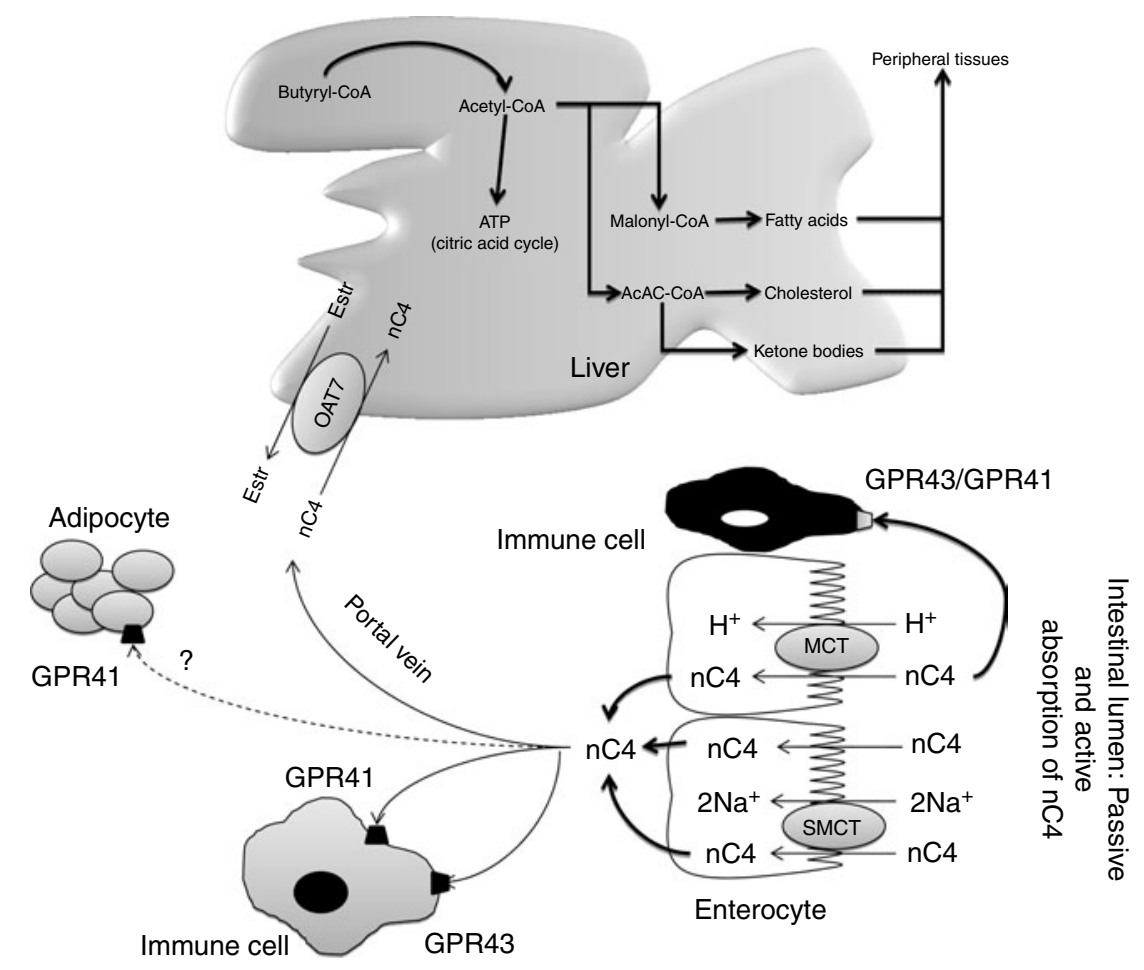

Fig. 2. Absorption of $n$-butyrate $(\mathrm{nC} 4)$ in the large intestine and subsequent metabolism. Butyrate transport with monocarboxylate transporters (MCT) is saturable and coupled with $\mathrm{H}^{+}$transport. Several receptors for butyrate have been identified and detected in a variety of tissues including fat tissue, but the highest expression has been found in immune cells. Butyrate prevents obesity and decreases body fat mass in mice, but the exact mechanism is unknown. After the intestine, butyrate can be metabolised in the liver to produce fatty acids, cholesterol and ketone bodies. In the peripheral blood, no significant concentration of butyrate is found. Oestr, oestrone sulfate; OAT7, organic anion transporter 7; GPR, orphan $\mathrm{G}$ protein-coupled receptor for SCFA; SMCT, Na-coupled monocarboxylate transporter. Adapted from Gupta et al. ${ }^{(73)}$ 
of histone deacetylase. But in the presence of butyrate, expression of SLC5A8 is again enhanced and it increases cell apoptosis ${ }^{(75)}$. Nevertheless, the lack of susceptibility for colon cancer in SLC5A8 - /- mice and the failure to detect a significant uptake of butyrate by SLC5A8 question the role of SLC5A8 both in butyrate transport and colon cancer suppression ${ }^{(76)}$

Two orphan G protein-coupled receptors (GPR) for SCFA, GPR41 (or FFA3) and GPR43 (or FFA2) have been isolated from the intestine ${ }^{(77-82)}$. FFA2 mRNA was detected in a variety of tissues, but the highest expression was found in immune cells, including polymorphonuclear cells, suggesting that SCFA might be involved in the activation of leucocytes. Indeed, recent studies in (FFA2) GPR43deficient mice $\left(\mathrm{Gpr} 43^{-/-}\right)$indicated that acetate administration may help in resolution of the inflammatory response $^{(83)}$. FFA3 has an even more widespread expression pattern than FFA2, including adipose tissues, pancreas, spleen, lymph nodes, bone marrow and peripheral blood mononuclear cells ${ }^{(81)}$. Abundant FFA2 and FFA3 expression was detected in the rat distal ileum and colon, and the human ascending colon ${ }^{(78,84,85)}$. Expression was limited to mucosal cells, and absent in enteric neurons and smooth muscle cells. Immunohistochemical staining with antiFFA2 and anti-FFA3 sera showed FFA2 and FFA3 immunoreactivity in enterocytes and enteroendocrine cells of open type ${ }^{(78,86)}$. The FFA3 immunoreactive enteroendocrine cells were less numerous than the FFA2 cells, and double-immunostaining for FFA2 and FFA3 revealed no common localisation in one cell. Both the FFA2- and FFA3immunoreactive enteroendocrine cells exhibited peptide YY, but no 5-hydroxytryptamine, expression, supporting the evidence for stimulation of peptide YY release by SCFA ${ }^{(78)}$ The FFA 2 and FFA3 distribution and physiological role in the GIT, involving sensing of luminal content, intestinal motility, secretion and innate immunity, have been recently reviewed by Karaki \& Kuwahara ${ }^{(86)}$.

In healthy rats fed a fibre-free or a RS-enriched diet and using $\left[1-{ }^{13} \mathrm{C}\right]$ butyrate intra-caecal perfusion, the flux of butyrate production was $0.7-1.8 \mu \mathrm{mol} / \mathrm{min}$ whereas portal flux was from 0.2 to $0.4 \mu \mathrm{mol} / \mathrm{min}$ and parietal utilisation from 0.9 to $1.8 \mu \mathrm{mol} / \mathrm{min}^{(87)}$. In unfed pigs with an intracaecal perfusion of $\left[1-^{13}\right] \mathrm{C}$-butyrate, the parietal utilisation of butyrate varied from 60 to $120 \mu \mathrm{mol} / \mathrm{min}$ when the concentration of perfused $\left[1-{ }^{13}\right] \mathrm{C}$-butyrate varied from 0 to $160 \mu \mathrm{mol} / \mathrm{min}$ (L Martin, unpublished results).

\section{Energy source for colonocytes}

In vitro studies have demonstrated that butyrate also represents the preferred energy-providing substrate for the colonic cells ${ }^{(4,88)}$. Colonocytes exhibit a great capacity to rapidly metabolise butyrate. Through fatty acid oxidation, butyrate is entirely oxidised into $\mathrm{CO}_{2}$ or used as a precursor for lipid synthesis ${ }^{(89)}$. In fact, butyrate is able to increase lipogenesis from acetyl-CoA or ketone bodies synthesis via the hydroxyl-methyl-glutaryl-CoA pathway ${ }^{(90)}$. Consequently, the synthesis of many key components of the intestinal epithelial tissue depends on butyrate metabolism (see later).
As butyrate is a key substrate for colonocytes, very small quantities reach the general circulation or portal vein. Guilloteau et al. ${ }^{(8)}$ did not observe any changes in plasma butyrate concentration in the peripheral circulation in calves. Nevertheless, the concentration of butyrate in the portal vein may vary according to the diet. Some substrates such as RS or oligosaccharides lead to substantial increases in butyrate concentration in the portal vein ${ }^{(91,92)}$. Hepatic uptake of butyrate is almost total. In the liver, butyrate metabolism also yields acetyl-CoA as in colonocytes.

In contrast to single-stomached animals, in vivo studies in steers revealed important butyrate uptake in the rumen as well as limited capacity to metabolise butyrate in the ruminal epithelium and liver. In cattle, butyrate absorption is saturable and if it exceeds the metabolic capacity, it affects rumen epithelial, hepatic nutrient metabolism and the nutrient supply of peripheral tissues ${ }^{(93)}$.

\section{Butyrate transport into the peripheral blood circulation:} is there proof for physiological direct effects?

As shown by Kristensen \& Harmon ${ }^{(93)}$ in cattle, substantial amounts of butyrate produced by rumen microbiota may be absorbed through the ruminal epithelium and induce a number of effects via the blood circulation. First, included at a low dose in the diet $(0.3 \%$ of DM), butyrate disappears from the upper GIT (mainly in the stomach). It is thought to be metabolised in the GIT wall because it is not found in blood $^{(8,94)}$. Nevertheless, when ingested with the diet, in specific conditions, butyrate would be measurable in peripheral blood $^{(95)}$ and seems to be able to act on peripheral organs (skeletal muscle, brown adipose tissue, liver, etc). Second, butyrate generated from dietary fibre fermentation at a high dose in the hindgut lumen (from 3 to $70 \mathrm{~mm})^{(96)}$ is quickly absorbed in rodents ${ }^{(97)}$ and transported via the portal vein to the liver. In humans the butyrate concentration in the portal vein is about $30 \mu \mathrm{M}$ whereas it is $12 \mu \mathrm{M}$ in the hepatic vein ${ }^{(1)}$. A significant amount of butyrate is detected in the portal vein but not in the peripheral circulation in pigs fed a diet enriched with resistant potato $\operatorname{starch}^{(98)}$. Similarly, using rye fibres as a RS source, butyrate concentration significantly increases in both the portal vein and peripheral circulation $^{(99)}$. In pigs, the direct perfusion of sodium butyrate in the caecum induces a dose-related increase of butyrate in the portal blood (L Martin, unpublished results). Butyrate, however, is not regularly detected in the peripheral blood even after a long period of perfusion with a supra-physiological solution of butyrate in the colonic lumen (L Martin, unpublished results). Taken together, these data suggest that butyrate can be absorbed from the gut and entirely metabolised either in the gut mucosa or in the liver, which makes a direct effect of butyrate via blood circulation unlikely. Indeed, Bloemen et al. ${ }^{(100)}$ showed that in human patients, no intestinally produced butyrate escaped the splanchnic area due to a highly efficient hepatic uptake.

\section{Butyrate and hepatic metabolism}

Only a small fraction of luminal butyrate can reach the liver via the portal vein. Nevertheless, the effect of butyrate on hepatic cell has been studied. In the liver, butyrate leads to 
the production of acetyl-CoA that enters into the citric acid cycle. It has been shown that the production of acetyl-CoA via the butyryl-CoA synthase pathway consumes $1 \mathrm{ATP} / \mathrm{mol}$ but due to the reoxidation of reduced compounds, the tissue ATP content is maintained. In an experiment using isolated perfused liver of rats, Beauvieux et al. ${ }^{(101)}$ observed that, unexpectedly, butyrate perfusion led to an impairment in energy metabolism, i.e. a decrease in net ATP content in comparison with acetate. The authors hypothesised that butyrate might impair mitochondrial activity inducing an uncoupling between the respiration chain and ATP synthesis. So, the effect of butyrate on hepatic metabolism appears to be close to that of longer-chain fatty acids. As long-chain fatty acids play a part in the pathogenesis of insulin resistance, the effect of butyrate should be considered in specific nutritional conditions (acarbose treatment, high level of dietary RS, etc) ${ }^{(102)}$.

When ingested, butyrate enhances glycogen synthesis in the liver at the same rate as glucose ${ }^{(103)}$. The authors demonstrated a clear effect on both a decrease in glucose oxidation and an increase in hepatic glycogen storage. They postulated that such a mechanism could be one of the molecular bases to explain the effect of dietary fibres on the prevention of insulin resistance.

Recently a new organic anion transporter (OAT7) was specifically identified in the liver ${ }^{(104)}$, exhibiting a significant transport activity for butyrate (Fig. 2). This transporter mediates the bidirectional transport of oestrone sulfate in exchange for butyrate. This exchange with oestrone sulfate might suggest a contribution (direct or indirect) of butyrate in liver steroid hormone metabolism. More fundamentally, the narrow substrate selectivity of OAT7 suggests that butyrate might participate in the efficient translocation of some sulfate conjugates without interference from the other anionic compounds such as bile salts. In other words, butyrate may play a role in the efficiency of liver detoxification pathways.

\section{Effects of butyrate on gastrointestinal epithelial cell functions}

Several studies have indicated that butyrate, besides providing epithelial cells with energy, markedly increases epithelial cell proliferation and differentiation, and improves colonic barrier function ${ }^{(105-108)}$. Butyrate operates as a signal metabolite in the homeostasis of colonocytes, regulating the balance between proliferation, differentiation and apoptosis ${ }^{(109)}$ (Fig. 3).

\section{Cell proliferation}

Earlier studies suggested that trophic effects on the GI epithelium are a result of SCFA. Butyrate is considered to have the strongest effect, that of acetate is weaker, and that of propionate is the weakest ${ }^{(110)}$. Butyrate ingestion is known to modify the microstructure of the small and large intestines in animals and humans ${ }^{(111-115)}$.

In enterocytes. In the small intestine, butyrate enhances proliferation, differentiation and maturation, and reduces apoptosis of normal enterocytes, mediated through its

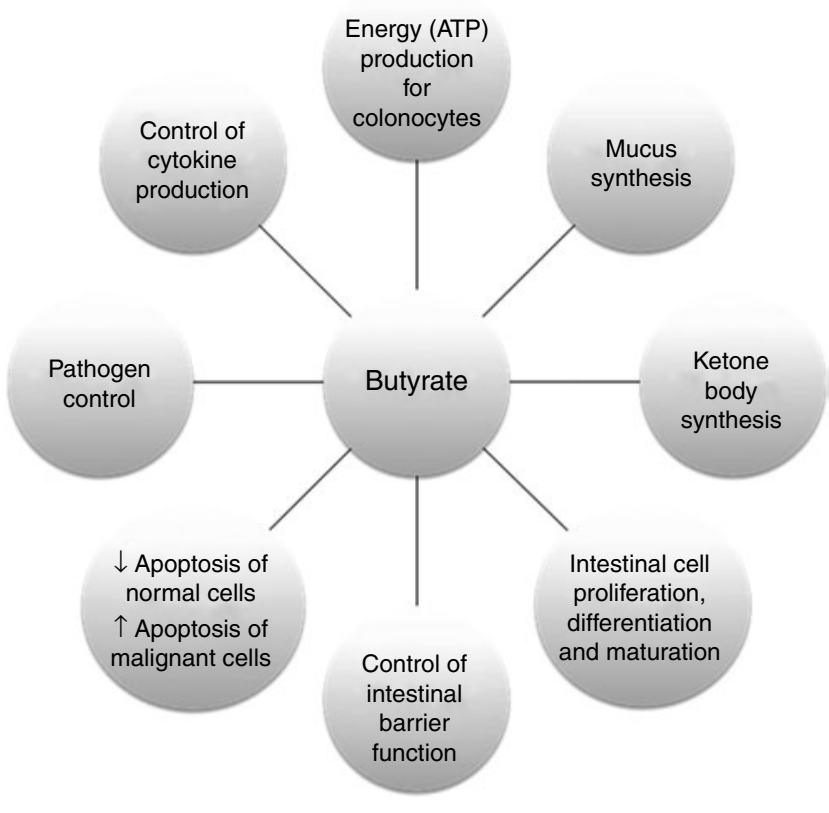

Fig. 3. Multiple effects (local) of butyrate in the intestine.

influence on gene expression and protein synthesis ${ }^{(116)}$. In the small intestine, the crypt depth and the villi height increase largely in butyrate-supplemented weaning or weaned pigs ${ }^{(94,117)}$. Interestingly, when infused in the colon, butyrate was shown to exert trophic effect on ileal and jejunal epithelial cells, presumably indirectly, through a neurohormonal mechanism ${ }^{(114,115)}$.

More recent molecular studies investigating cell proliferation, damage, and programmed death (mainly apoptosis) revealed that butyrate speeds up intestinal mucosa maturation during the development or repair after injury ${ }^{(112)}$. Calves supplemented with low doses of sodium butyrate showed a significantly increased mitotic index in the upper jejunum but not in the duodenum or ileum as compared with controls ${ }^{(8)}$. However, changes in the mitotic index were not reflected in villi length and tunica mucosa thickness.

In colonocytes. In contrast to the upper intestine, in the large intestine the trophic effects appeared only at the place of butyrate administration. In rodents and swine, all studies showed that the mass of large-bowel tissue is higher in animals fed a butyrate-producing diet, compared with controls $^{(118-120)}$. An increase in the length of the colon is repeatedly reported. Increased butyrate concentrations are associated with morphological changes of the mucosa ${ }^{(121)}$. The crypt depth is significantly increased in pigs fed a raw potato starch diet associated with a decrease in the apoptotic activity. The secretory activity, but not the number, of epithelial growth factor-secreting goblet cells is nearly 2 -fold increased compared with the controls. Simultaneously, the activity of two anti-apoptotic-regulating proteins is increased (Bcl-2; Bak). An overall reduction of apoptosis was detected without any effects on mitosis. Therefore, it was concluded that the main butyrate effect, 
in non-tumoural cells, is a shift of apoptosis towards the middle and basal compartments of the crypts. Conversely, in the absence of butyrate, there is massive apoptosis of colonocytes $^{(122)}$.

Two plausible mechanisms are used to explain the increased proliferation index of colonic mucosa in physiological conditions ${ }^{(123)}$. The first mechanism is that butyrate is the main energy source for colonocytes and more energy stimulates cell growth. The second mechanism involves the stimulation of the release of GI peptides and/or growth factors by butyrate acting on cell proliferation.

\section{Apoptosis}

In normal cells, butyrate acts as a survival factor but it is an inducer of apoptosis in human colonic carcinoma cells ${ }^{(122)}$. In an in vivo study in pigs, inulin-coated butyrate led to a reduction of apoptosis in the ileal mucosa and an increase in the length of ileal villi although it had no effect on cell mitosis $^{(118)}$. Bailón et al. ${ }^{(124)}$ evaluated the effects of butyrate on the proliferation and activation state of different cell types involved in inflammatory bowel disease: intestinal epithelial cells, macrophages and T-lymphocytes, using primary non-transformed cultures and established cell lines. Low concentrations of butyrate inhibited the proliferation of all immune cell types, whereas it induced apoptosis only in activated T-lymphocytes, non-differentiated epithelial cells and macrophage cell lines, but not in differentiated epithelial cells or primary macrophages. The induction of apoptosis was mediated by caspase-3/7 activation (mitochondrial pathway). Butyrate was only able to modify cell activation, measured as expression of inflammatory cytokines, in those cell types in which apoptosis was induced.

Apoptosis is an important regulatory process against cancer but various mechanisms can lead cells into a proapoptotic state. Zeng \& Briske-Anderson ${ }^{(125)}$ showed that prolonged butyrate treatment in vitro (HT1080 cells) increased the expression of both pro-metastatic and antimetastatic genes but the net effect was an inhibition of pro-metastatic and an activation of anti-metastatic genes. Butyrate also arrested cell growth and migration and invasion of HT1080 cells by inhibiting histone deacetylases, and also by acting on non-histone proteins ${ }^{(126)}$ at the first stages of DNA damage. Once DNA is damaged, butyrate seems to be ineffective. The absolute concentration of butyrate is also very relevant, as low amounts of butyrate enhance cell proliferation while high amounts inhibit it.

In the human colon cancer RKO cell line, butyrate induced apoptosis through a mechanism involving the c-Jun-N-terminal kinase (JNK) mitogen-activated protein kinase (MAPK) kinase pathway ${ }^{(127)}$. In contrast, in neutrophils obtained from healthy human volunteers, butyrate increased apoptosis irrespective of their activation state, by factors other than MAPK and GPR, and their mechanisms probably relate to their histone deacetylase inhibition activity, which may control a1 mRNA expression $^{(128)}$.

In the large intestine, cell proliferation, differentiation and positional localisation along the crypt axis are governed by several signalling pathways including the
Wnt/ $\beta$-catenin pathway ${ }^{(129)}$. When Wnt signalling is activated, normal cell differentiation and proliferation are modified, leading to probable cancer genesis ${ }^{(129)}$. Furthermore, the relative levels of Wnt signalling determine whether cells proliferate or go to apoptosis ${ }^{(126)}$, since several in vivo studies support the evidence that increased activation of Wnt transcriptional activity enhances apoptosis in some cancerous cells. In vitro studies showed that butyrate hyper-induced Wnt transcriptional activity in some tumour cell lines ${ }^{(130)}$. The authors conclude that both relatively high and relatively low level of canonical Wnt transcriptional activity can lead to cancerous cell apoptosis, and that cells involved in the tumorigenic process due to Wnt signalling are more vulnerable to butyrate action.

\section{Beneficial effects on performance and intestinal health}

Studies with oral administration of butyrate showed that butyrate can improve growth performance in production animals. The effective doses of sodium butyrate were fixed between 1 and $4 \%$ of DM intake, and protection of the molecule by microencapsulation in lipid matrix improved its efficiency. Moreover, slow release of butyrate from a lipid matrix prevented its rapid metabolism in the stomach and upper small intestine, thereby increasing the area under the influence of the molecule ${ }^{(131,132)}$. Butyrate was found to have widespread positive effects on growth, digestibility and feed efficiency through the modulation of cell proliferation, differentiation and function in the GIT, especially mucosal epithelial cells, and on defence systems (barrier function, antimicrobial potency, immune system) in healthy and sick animals $(2,94,133-138)$

Effects on growth performance and digestive efficiency. Dietary supplementation with butyrate enhanced growth rate and improved the feed conversion rate in calves before and during weaning ${ }^{(8,131,139)}$ and in piglets ${ }^{(2,140-143)}$. Studies in neonatal ${ }^{(112)}$ and in weaned ${ }^{(111,138)}$ piglets showed that the ingestion of butyrate resulted in improved performance, which was further improved if butyrate was fed sooner rather than later post-birth. Butyrate supplementation during the suckling period had no influence on ileal apparent digestibility, but it significantly improved the faecal apparent digestibility of feed components after weaning ${ }^{(111)}$. In these studies, butyrate supplementation delayed gastric emptying, which may suggest that increased gastric retention (longerlasting gastric phase of digestion, slower digesta flow to the intestine) is beneficial for digestive processes ${ }^{(144,145)}$. In the newborn calves, the effect of butyrate supplementation both to the milk replacer and starter diet reduced diarrhoea, and led to an improved health status in the first weeks of life ${ }^{(131)}$. In calves fed milk formula based on soyabean protein, butyrate supplementation improved the DM digestibility and the digestibility of major components of the diet ${ }^{(146)}$. Moreover, the concomitant addition of butyrate to milk replacer and starter mixture may stimulate rumen development. Thus, the weight of the rumen (percentage of the whole stomach) was increased at the expense of the abomasum, and the ruminal papillae length and width were increased ${ }^{(131)}$, improving the absorptive surface of the rumen. 
The pancreas weight and the pancreatic protein content were not modified by butyrate supplementation $(3 \mathrm{~g} / \mathrm{kg} \mathrm{DM})$ in neonatal pigs and calves ${ }^{(8,112)}$. In contrast, the mitotic index increased and apoptotic index decreased in exocrine pancreatic cells in calves ${ }^{(147)}$. These results suggest that pancreatic growth was not modified by butyrate supplementation; rather, the pancreatic cell turnover was accelerated. This corroborates with earlier studies demonstrating promitotic effects of butyrate in the healthy gut of weaned pigs in vivo, though without effects on villous-crypt architecture $^{(142)}$ and supports the suggestion that animals should receive butyrate supplementation after birth as soon as possible. Preliminary studies by Pietrzak et al. ${ }^{(148)}$ demonstrated that butyrate supplementation exerted a promitotic and anti-apoptotic effect in the small-intestinal mucosa in calves. This in turn elevated the mitotic:apoptotic ratio in butyrate-treated calves and resulted in increased villi height and intestinal absorptive surface.

Taking into account all of these results, butyrate may be considered as an important factor controlling early postnatal development of the $\operatorname{GIT}^{(135)}$ and it seems that the digestive process in the intestinal lumen could be more efficient in animals fed a butyrate-supplemented diet.

Effects on digestive secretions. In piglets, pre-weaning supplementation of butyrate was found to increase the densities of gastric parietal cells ${ }^{(138)}$, suggesting an increase in gastric acid secretion. Indeed, the effects of butyrate had little association with the enhanced acidity of the ingesta, as suggested by Manzanilla et al. ${ }^{(94)}$. Intra-ileal administration of butyrate in pigs caused an acute increase of trypsin and protein outputs ${ }^{(149)}$. Duodenal butyrate infusion, however, did not change the mean flow rate of juice and proteins for $1 \mathrm{~h}$ after initiating administration, in contrast to observations after oral supplementation. Moreover, in contrast to ingestion, butyrate infusion decreased the mean flow rate of chymotrypsin ${ }^{(146)}$.

In calves, butyrate supplementation in milk formula increased total daily pancreatic secretions. For pancreatic juice, this increase was most important from 12 to $17 \mathrm{~h}$ after the morning meal ${ }^{(146)}$. In the same experiment, it was shown that during the $3 \mathrm{~h}$ postprandial period, oral butyrate supplementation led to a physiological postprandial decrease of pancreatic secretion. Likewise, butyrate supplementation was accompanied by a $50 \%$ increase in activity of elastase II in pancreatic tissue ${ }^{(8)}$. These effects may be relevant for overall digestive processes, because during the postprandial $2-3 \mathrm{~h}$ the arrival of gastric digesta in the duodenal lumen is the highest $\mathrm{t}^{(150,151)}$. These observations help to explain, at least in part, the increase of nutrient digestibility by butyrate supplementation. This hypothesis is supported by the fact that lipase is the pancreatic component that was the most affected, in parallel with fat digestibility ${ }^{(146)}$.

In calves and pigs, the activities of brush-border dipeptidylpeptidase IV, lactase and maltase in the mid-jejunum and aminopeptidases $\mathrm{A}$ and $\mathrm{N}$ in the distal jejunum were increased ${ }^{(8,141)}$. Similar results were reported in other species (i.e. mouse, rat, guinea-pig, vole, pig, sheep and goat) when butyrate was used in in vitro preparations, as an additive in the diet as well as after intravenous (in conscious or anaesthetised animals) or intraduodenal administration. Although it is realised that the response can vary between species ${ }^{(141,152-157)}$, the data as a whole suggest that butyrate in mammalian species acts directly at the GIT level rather than after its absorption. After oral administration of physiological doses of butyrate, butyrate could act directly on the GIT secretions in the stomach and proximal duodenum but indirectly in the lower small intestine.

Effects on the defence system. In the GIT, the digestive defence system includes the mucous layer in the gut (physical barrier), the innate and adaptative immune systems and the expression of heat-shock proteins (HSP). Butyrate has been found to have a profound impact on the immune system of human subjects and rodents ${ }^{(158)}$ and to exert anti-inflammatory properties in vivo and in vitro ${ }^{(159-161)}$. Surprisingly, butyrate supplementation reduced the small intestine mucosal mass ${ }^{(111)}$. This would suggest that butyrate can interfere with intestinal protein metabolism $^{(162,163)}$, following a reduced bacterial load and possibly a lower inflammation locally.

Butyrate administration into the lumen of isolated vascularly perfused rat colon $(5 \mathrm{mM})$ enhanced mucin secretion, but increasing the concentration up to $100 \mathrm{~mm}$ provoked a gradual decrease in mucus discharge ${ }^{(164)}$. In piglets fed a butyrate-supplemented diet, the number of colonic goblet cells was significantly increased ${ }^{(94)}$. In milk-fed calves, butyrate enhanced HSP27 and HSP70 expression in the abomasum and in the colon, but not in the small intestine ${ }^{(8)}$. Perhaps the heat-shock response was induced indirectly through increasing the numbers of microbials in GI segments (prebiotic activity of butyrate). This finding suggests that butyrate used at low doses may have cytoprotective effects.

Effects on digesta composition (microbiota). There are few publications studying the effects of inclusion of butyrate at a low dose in diets for animal and human species on intestinal microbiota. The relationship between lactobacilli and enterobacteria populations has traditionally been considered as an index of desirable or undesirable bacteria in pigs, relating a high index with a greater resistance to intestinal disorders ${ }^{(165)}$. Adding butyrate to diets promoted greater mean values in this ratio ${ }^{(166)}$. Galfi \& Bokori ${ }^{(140)}$ observed changes in the ileal microbiota with a decrease in the proportion of coliform bacteria and a simultaneous increase of lactobacilli. Van Immerseel et al. ${ }^{(167)}$, using microencapsulated butyrate in young chickens, also demonstrated a decrease in the caecum colonisation of Salmonella after an experimental infection. It was reported that oral butyrate supplementation would not influence the number of total bacteria inhabiting different sections of the GIT but rather promote the largest changes in the composition of the jejunal microbiota and in the ecological structure and metabolic activity of the microbial ecosystem of the large intestine ${ }^{(166)}$. These authors suggested that such changes in the upper GIT could potentially modify the fermentable material reaching the large intestine and, therefore, modify the microbial activity at the faecal level. 


\section{Protecting effect against inflammatory intestinal diseases}

In humans, effects of lower butyrate concentrations have been reported in patients with ulcerative colitis compared with healthy subjects and there is evidence to suggest that the metabolism of butyrate is impaired in ulcerative colitis ${ }^{(168)}$. In experimental colitis, colonocyte oxidation of butyrate is markedly suppressed ${ }^{(169)}$, leading to reduced cellular ATP levels and decreased cell metabolism. Many studies have demonstrated that delivery of butyrate through local enema or diet results in a protective or therapeutic effect against inflammatory bowel diseases ${ }^{(170,171)}$. The role of butyrate in colitis, however, remains complex. Butyrate exerts trophic effects on the colonic epithelium and is able to modify the inflammatory response by inhibiting, for instance, NFKB activation and HSP expression. In dextran sulfate sodiumtreated rats, it has been shown that butyrate is efficient in reducing inflammation and in restoring intestinal permeability. The mechanisms of action are numerous and, among them, the inhibition of HSP70 synthesis has been indicated $^{(161)}$. As mentioned earlier, the effects of butyrate could be different in normal and cancerous cells, such as for apoptosis. In HT-29 cell lines, butyrate seems to be able to prevent inflammation by reducing both cellular permeability in the colon through PPAR $\gamma$ activation and the expression of IL-8 genes ${ }^{(172)}$. Nevertheless, mechanisms for butyrate action are not always well known. Butyrate can affect several components of the colonic barrier, leading to an improvement in epithelial colonic defence mechanism: mucin (MUC) production, improvement of intestinal epithelial permeability and modulation of pro-inflammatory cytokines via impairment in $\mathrm{NF \kappa B}$ activation. In vitro, butyrate increases expression of the MUC gene ${ }^{(173)}$ but the effect seems to be dose dependent ${ }^{(164)}$. In Caco- 2 cells, a decrease in butyrate increases intestinal permeability ${ }^{(174)}$ and butyrate up-regulates lipoxygenase 5-LOX, 12-LOX and 15-LOX mRNA expression ${ }^{(175)}$. The authors suggested that LOX activated by butyrate may induce cellular differentiation and in addition it could control tight-junction permeability. A recent paper showed that one possible mechanism of action of butyrate on tight junctions involves the AMP-activated protein kinase, but how this kinase is activated by butyrate remains unclear ${ }^{174)}$. One hypothesis could be that butyrate enhances the energetic state of the cell (increase of cellular ATP content).

In animals and in humans, dietary fibre and SCFA are stimulators of both GLP-1 and GLP-2 synthesis. Butyrate appears to be the strongest stimulator of GLP- $2^{(176)}$. There is already a great number of GLP-2 effects recognised in the intestine: suppression of gastric acid secretion, decrease in gastric motility, enhancement of intestinal nutrient transport, increase in intestinal blood flow, increase in intestinal cell proliferation, enhancement of intestinal barrier function and inhibition of crypt cell apoptosis. Recently, GLP2 has emerged as a possible treatment option against intestinal bowel diseases ${ }^{(177)}$.

\section{Mechanisms of action of butyrate in physiological and pathological conditions}

\section{In physiological conditions}

Action on regulatory peptides. Following ingestion of a butyrate- or butyrate precursor-enriched diet, a common effect of butyrate on the architecture of the GIT wall can be found since it stimulates proliferation, differentiation and maturation, and reduces apoptosis in the cells. The effects on the forestomach, stomach and hindgut seem to be direct $^{(131,178)}$, whereas the effects on the pancreas and small intestine are probably indirect. It is increasingly recognised that intestinal development (growth and maturation) and digestive functions depend on a unique neuro-hormonal and immune-regulatory system mediated by a multitude of regulatory substances ${ }^{(179)}$. Thus, it has been suggested that the possible effect of butyrate on GIT development is by its effects on bioactive peptides or hormones secreted into the blood and/or locally produced in the $\operatorname{GIT}^{(8,146)}$ ( $\mathrm{J}$ Flaga, unpublished results). Two candidate regulatory peptides are gastrin and cholecystokinin, known for their trophic effects in the upper gut. Cholecystokinin and secretin are also known to control the secretion of pancreatic juice and bile. However, no change in the plasma concentration of gastrin, cholecystokinin and secretin or in the expression of cholecystokinin or gastrin receptors was observed in calves fed with a butyrate-enriched diet. These results are in contrast to an enhanced efficiency of duodenal digestive functions and suggest that these peptides do not mediate the butyrate effects ${ }^{(8,146)}$. These findings disagree with data obtained from in vitro cell-culture studies showing increased gastrin mRNA expression and gastrin secretion during butyrate treatment ${ }^{(180)}$. Inhibition of postprandial circulating somatostatin in calves ${ }^{(8)}$ may be explained by a direct effect of butyrate on somatostatin-secretin cells. Plasma pancreatic polypeptide, which inhibits pancreas and gut secretions, was reduced in newborn piglets following the ingestion of a butyrate-supplemented milk replacer ${ }^{(112)}$

The effects of butyrate on the upper small intestine could involve the GLP-2 pathway in piglets ${ }^{(113)}$ and in calves ${ }^{(131)}$ in agreement with the fact that GLP-2 is considered an important endocrine signal activating intestinal adaptation, cell survival and proliferation in newborn mammals ${ }^{(181,182)}$. Also, an increase in plasma enteroglucagon levels was correlated with the increase in the villus height and crypt depth in the small intestine ${ }^{(159)}$. Finally, there was an increase in the expression of insulin-like growth factor-1 receptors in the jejunum of butyrate-supplemented calves ${ }^{(8)}$. These results suggest that part of the effects of butyrate is likely to be mediated by insulin-like growth factor- $1^{(183)}$.

Patients fed dietary fibre have modified acute postprandial responses for glucose, insulin and gut hormones ${ }^{184)}$. Among gut hormones, GLP-1 stimulates insulin secretion, reduces the rate of gastric emptying, increases insulin sensitivity and decreases energy intake ${ }^{(185)}$. As butyrate is able to increase ileal and colonic proglucagon mRNA expression and postprandial GLP-1 concentrations in rats, it probably contributes indirectly via GLP-1 to glucose and energy metabolism.

Action on the defence system. Butyrate decreases in vitro lymphocyte proliferation in mice $e^{(186)}$ and in rats ${ }^{(187)}$. In $\mathrm{T}$ helper 1 cells butyrate acts as a cell anergy factor. When activated, T helper 1 cells enter into the G1 phase of the cell cycle. However, when antigen-presenting cells are in the presence of butyrate, $\mathrm{T}$ helper 1 cell proliferation is blocked $^{(188)}$. In this case, butyrate requires T-cell receptor 
ligation and $\mathrm{Ca}$ mobilisation ${ }^{(188)}$. Moreover, butyrate increases the secretion of IL-10 ${ }^{(189,190)}$, and decreases the secretion of interferon- $\gamma^{(189)}$ by activated human lymphocytes in vitro. Butyrate also decreases the ex vivo production of inflammatory cytokines in intestinal biopsies of humans suffering from Crohn's disease, and reduces the severity of 2,4,6-trinitrobenzenesulfonic acid-induced colitis in rats ${ }^{(160)}$. Butyrate decreases intestinal expression levels of TNF $\alpha$, IL-1 $\beta$ and IL-6 in patients with Crohn's diseases $^{(158)}$. In piglets aged $40 \mathrm{~d}$, Le Gall et al. ${ }^{(111)}$ have observed a tendency to a reduced expression of IL-8, in agreement with the results of Gibson \& Rosella ${ }^{(191)}$ who have demonstrated that, in vitro, IL-8 secretion by colonic crypt cells is suppressed by butyrate.

Members of the HSP family have been implicated in an ever-growing number of cellular activities including the effects of microbial agents ${ }^{(192)}$. It is reasonable to think that butyrate may affect (1) microbial composition in the intestinal lumen and bacterial number (probiotic effect) and this action may influence HSP expression in the gut tissues, and (2) the HSP expression in the gut mucosa by itself. Thus, cell protection is possibly enhanced because of chaperone activity, mostly ascribed to HSP70 family members ${ }^{(193)}$. It was shown that HSP25/27 need SCFA for basal expression in epithelial cells of the colon and in the distal small intestine in vivo in the rat ${ }^{(194,195)}$, which is in agreement with the results obtained in the calf ${ }^{(8)}$. In vitro, SCFA enhance the expression of HSP25/27 in a dose- and time-dependent manner, an effect that is transcriptionally regulated ${ }^{(196)}$, and protect rat intestinal epithelial cells from injury ${ }^{(194)}$. The HSP response is a universal response to cell injury ${ }^{(197)}$ that could be associated with a stress response of the GIT epithelium.

\section{In pathological conditions}

Butyrate can hardly escape the splanchnic area; it seems able to act as a systemic mediator in several conditions (Fig. 4).

Obesity and diabetes. In obese mice fed a high-fat diet, addition of butyrate to the diet (5\% of the meal) reduced insulin resistance and increased energy expenditure ${ }^{(95)}$. In the treated group, butyrate prevented obesity because there was no increase in fat mass after 16 weeks of treatment on the high-fat diet. Butyrate increased thermogenic function in the mice, and treated mice had smaller brown adipocytes than their control counterparts. The expression of two thermogenesis-related genes (PPAR $\gamma$ coactivator- $1 \alpha$ (PGC-1 $\alpha)$ and uncoupling protein-1 (UCP-1)) was increased in the butyrate group. Fasting insulin was also $50 \%$ lower in the butyrate group, and treated mice showed much better response to insulin during the intraperitoneal insulin tolerance test. In addition, butyrate administration through food supplementation was effective in treating obesity in dietary obese mice. In agreement with these results, several studies showed that rats fed RS (a 'butyrogenic' dietary fibre) have lower body fat than their control counterparts. Moreover, dietary RS up-regulated hypothalamic pro-opiomelanocortin (POMC) expression

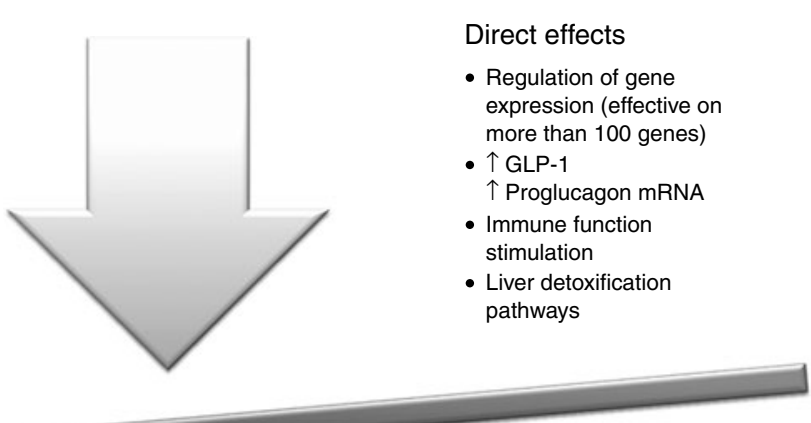

Indirect effects?

- $\uparrow$ Feed conversion rate

- $\uparrow$ Growth performance

- $\uparrow$ Pancreatic secretions (lipase +++)

- Increase of body

thermogenesis

- Control of body adiposity

(through POMC expression?)

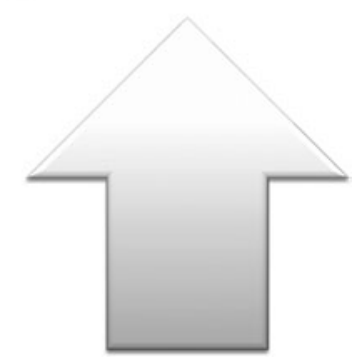

Fig. 4. Overview of the multiple effects of butyrate as a systemic factor. GLP, glucagon-like peptide; POMC, pro-opiomelanocortin.

in rats ${ }^{(198)}$. Thus, one mechanism of decreased body fat is probably linked to POMC expression.

Several neuroendocrine factors are involved in the regulation of food intake. Among them, peptide YY, GLP-1 and leptin have been widely studied. Moreover, both GLP-1 and leptin are implicated in the pathogenesis of obesity and diabetes. Butyrate directly increases peptide YY/proglucagon gene expression in vitro ${ }^{(199)}$. Such a result is observed in vivo in RS-fed rats. Such findings may lead to the hypothesis that butyrate could also act as a pathogenic factor in some diseases by increasing food intake. Leptin is thought to be a sensor of energy stores in the body via the body fat mass. Numerous data demonstrate that leptin is a probable humoral link between metabolism and several neuroendocrine systems. In vitro, butyrate down-regulates leptin expression in rat anterior pituitary cells ${ }^{(200)}$. In fact, in vitro, butyrate seems to be able to regulate the synthesis of some pituitary hormones. Nevertheless, to date these effects of butyrate have not been confirmed in in vivo studies and there is also apparent conflict between the results of clinical studies and animal performance studies. In clinical trials (inflammatory bowel disease, Crohn's disease, ulcerative colitis, etc) it was shown that the body weight of patients treated with butyrate increased. It was confirmed in patients with Crohn's disease who received microencapsulated butyrate (R Zabielski, unpublished results). Concerning animal production, body-weight gain increases following butyrate treatment. The appetite is probably increased and the intestinal microstructure could be improved. Thus, it is possible that in 'healthy overweight' individuals the response to butyrate may be different from that in patients with inflammatory bowel disease.

Protection against oxidative damage. Inflammatory bowel diseases are characterised by recurrent chronic 
inflammation. The inflammatory cells produce large quantities of reactive oxygen species in the deep layers of the bowel wall that pave the way for colorectal cancer ${ }^{(201)}$ Butyrate could modulate the level of oxidative stress both in vitro and in vivo. In isolated human colonocytes and in HT29 tumour cells, butyrate shows a protective effect against oxidative DNA damage induced by $\mathrm{H}_{2} \mathrm{O}_{2}^{(202)}$. In healthy colon cells, butyrate modulates the expression of genes associated with oxidative stress ${ }^{(203)}$. In humans, the expression of human catalase, human cyclo-oxygenase 2 and human metallothionein $2 \mathrm{~A}$ is enhanced, whereas that of glutathione reductase, $\mathrm{PG}$-endoperoxide synthase 2 and superoxide dismutase 2 is lowered. The authors concluded that changes could reduce oxidant-damaging effects and protect cells from cancerogenesis.

Nevertheless, the response to butyrate treatment showed large variability among donors. Rectal administration of butyrate enhances the colonic antioxidant capacity of healthy patients ${ }^{(204)}$. The rectal infusion clearly increases total glutathione production in perfused biopsies. The expression of several genes is also modified: increase of glutathione peroxidase 1, glutathione peroxidase 3 and glutamate-cysteine ligase catalytic sub-unit, and decrease of glutathione peroxidase 2, glutathione reductase, glutathione synthetase and xanthine dehydrogenase. Notably, the effects of butyrate are not long lasting and disappeared soon after finishing the infusions.

Mechanism of pathogen control against bacteria. Acetate, propionate and butyrate are weak acids with $\mathrm{pKa}$ values of approximately $4 \cdot 8$. They have bacteriostatic and bactericidal properties depending on the physiological status of the bacteria and the physico-chemical characteristics of the external environment ${ }^{(205)}$. The concentration of the undissociated form, which can diffuse freely across the bacterial lipid membrane into the bacterial cell, is affected by $\mathrm{pH}$. Therefore $\mathrm{pH}$ is a key determinant of effectiveness $^{(206)}$. A $\mathrm{pH}<4.8$ increases the availability of the undissociated acid that once internalised into the more alkaline cytoplasm, dissociates into anions and protons, thereby reducing the internal $\mathrm{pH}^{(207)}$. But bacteria need to maintain a near-neutral $\mathrm{pH}$ in their cytoplasm to sustain functional macromolecules. Exporting the excess of protons requires cellular ATP and may result in depletion of cellular energy leading to cellular damage and/or death. The accumulation of anions would be the primary toxic effect of organic acids ${ }^{(206)}$. Some organisms allow a decline of their internal $\mathrm{pH}$ and are therefore more resistant to organic acids than others. Also inherent resistance via exclusion of the antimicrobial chemical, secretion of the toxic compound or metabolic detoxification can influence the efficacy of the organic acids ${ }^{(206)}$. SCFA are proposed to interfere with cytoplasmic membrane structures and membrane proteins, uncoupling electron transport and therefore reducing ATP production. This interference can also lead to damage in the cytoplasmic membrane, resulting in leakage or disruption of outer membrane permeability. Less direct antibacterial action is the influence of organic acids on macromolecular synthesis or nutrient transport ${ }^{206,208)}$

SCFA are used in pathogen control in the field, especially against Salmonella in poultry and pigs. In chickens, during the early stages of life the multiplication of Salmonella is difficult to prevent by endogenously produced SCFA. As it is of great importance to prevent initial colonisation of Salmonella, and because food is a major source for Salmonella introduction to the farm, drinking water and food are commonly acidified. By creating a barrier at the level of drinking water and food, recontamination with pathogens is believed to be prevented. In food, the antibacterial activity of SCFA depends on the temperature and moisture. Since minimal inhibitory concentration values increase at increasing $\mathrm{pH}$ values, quite high concentrations of SCFA are needed in the gut to achieve a direct antimicrobial effect. The powder-form acids used as a feed additive exert their effects in the upper GIT. When using acids coated on a carrier or in encapsulated form, the acids are thought to be protected from the intestinal environment which allows the control of their site of action as well as the velocity of release and dissociation ${ }^{(134)}$. This is of importance, as the main colonisation places for Salmonella in chickens are the caeca ${ }^{(209)}$. In epithelial cell lines and primary chicken caecal epithelial cells, the invasion of Salmonella typhimurium and S. enteritidis is suppressed when the strains are pre-incubated in growth media supplemented with various concentrations of butyrate, while pre-incubation in acetate-supplemented medium results in an increased invasion ${ }^{(210)}$. The effect of SCFA on Salmonella invasion is explained by changes in expression patterns of genes of Salmonella pathogenicity island (SPI)-1, which encodes for regulatory and effector proteins and structural components of a needle complex, necessary for invasion in epithelial cells. DNA microarrays of both $S$. typhimurium and $S$. enteritidis grown in media supplemented with low concentrations of butyrate show specific down-regulation of SPI-1 while no alterations in metabolic gene expression are seen when compared with control samples ${ }^{(211)}$. An opposite effect is observed in enterohaemorrhagic Escherichia coli, a human pathogen causing severe diarrhoea. Nakanishi et al. ${ }^{(212)}$ showed that butyrate enhances the expression of virulence-associated genes in a concentration-dependent manner. Even at low concentrations, butyrate triggers the adherence-related genes, leading to efficient colonisation of the target niche ${ }^{(212)}$.

Besides altering the pathogenicity of bacteria by antimicrobial effects or by an effect on virulence gene expression, butyrate has some effects on the host that can significantly contribute to protection against pathogens. Via in vivo experiments, it was shown that butyrate prevents Clostridium perfringens-induced necrotic enteritis lesions in broiler chickens ${ }^{(213)}$. Because butyrate has no significant antimicrobial effect against Clostridium perfringens, it can be concluded that the observed results are due to effects of butyrate on the host. A possible explanation could be a faster replacement of epithelial cells in the necrotic foci by the trophic effects of butyrate. Similar results can be concluded for cell invasion assays using Campylobacter jejuni. Butyrate-treated Caco2-cells were protected from Campylobacter jejuni invasion in a concentration-dependent manner ${ }^{(214)}$. This effect was explained by the butyrateinduced differentiation of the Caco- 2 cells, as differentiated monolayers cells are less susceptible to Campylobacter jejuni invasion than undifferentiated cells ${ }^{(215)}$. 


\section{Concluding remarks and perspectives}

The present paper underlines that butyrate is a natural component of the biological liquids and tissues as well as of digestive contents and that butyrate has particular properties among the SCFA. It is produced in small quantities in neonates, but its production greatly increases during the development of the hindgut and/or forestomachs. In omnivorous animals and in man, RS and fructooligosaccharides are essential precursors for butyrate production in the hindgut.

The present paper aims to highlight the biological role of butyrate, whether it is naturally produced by the GI microbial ecosystem or orally ingested as a feed additive. Since in most circumstances butyrate seems to act in a similar way when it is in the acid or salt form it appears that only the radical [CH3-CH2-CH2-COO-] is of major importance. Under physiological conditions, the increase in performance could be explained, at least in part, by the increased nutrient digestibility thanks to a delayed gastric emptying and optimised $\mathrm{pH}$ of gastric digesta. This first phase of digestion leads to a more efficient degradation of dietary components in the gut, which are further processed by pancreatic and intestinal enzymes stimulated by butyrate entering the small intestine. Moreover, a decrease in diarrhoea was observed perhaps in relation to modification of ileal microbiota as well as that of large bowel content and also to an improvement of epithelial integrity and defence systems. The key consequences are beneficial systemic effects on feed efficiency, growth rate and adiposity despite the fact that butyrate remains undetectable in the peripheral blood. Thus, butyrate could have an indirect effect on the upper GIT or a direct effect on the lower GIT.

Numerous mechanisms are believed to contribute to the beneficial effects of butyrate; however, many remain unclear. In the digestive tract and in both situations (low and high doses of butyrate in the lumen), butyrate is able to modify development or rebuilding of the tissues. Thus, trophic effects are on cell proliferation, resulting in a faster repair of necrotic tissues. There is also an indirect way of butyrate action since this molecule is not found in blood. This effect probably involves substances produced by the hormono-neuro-immuno system. Butyrate could also act on the intestinal microbiota composition. Thus, the common mechanism of butyrate's indirect action on host GIT tissue cells and on micro-organisms is at the molecular level, as butyrate was shown to operate at the first stages of DNA damage in cell lines.

In animal production, studies showed that ingested butyrate is a helpful feed additive as it allows pathogen control, increases ration digestibility and growth rate, and decreases oxidative stress and cytokine synthesis, even at very low doses. The effects are predominantly noteworthy in neonates and before weaning in piglets and calves. We suggest that such effects could be developed to extend the use of butyrate in the field of animal production and also considered for new applications in human nutrition.

\section{Acknowledgements}

This research received no specific grant from any funding agency in the public, commercial or not-for-profit sectors.
The authors greatly acknowledge Mrs Victoria Frances O'Gorman for the English revision of the manuscript.

P. G. was the initiator of the review and all authors contributed equally to the preparation of the paper.

There are no conflicts of interest.

\section{References}

1. Bergman EN (1990) Energy contributions of volatile fatty acids from the gastrointestinal tract in various species. Physiol Rev 70, 567-590.

2. Partanen KH \& Mroz Z (1999) Organic acids for performance enhancement in pig diets. Nutr Res Rev $\mathbf{1 2}$ $117-145$.

3. Poirier H, Degrace P, Niot I, et al. (1996) Localization and regulation of the putative membrane fatty-acid transporter (FAT) in the small intestine. Comparison with fatty acidbinding proteins (FABP). Eur J Biochem 238, 368-373.

4. Roediger WE (1982) Utilization of nutrients by isolated epithelial cells of the rat colon. Gastroenterology 83, 424-429.

5. Pender SL, Quinn JJ, Sanderson IR, et al. (2000) Butyrate upregulates stromelysin-1 production by intestinal mesenchymal cells. Am J Physiol Gastrointest Liver Physiol 279, G918-G924.

6. Inagaki A \& Sakata T (2005) Dose-dependent stimulatory and inhibitory effects of luminal and serosal $n$-butyric acid on epithelial cell proliferation of pig distal colonic mucosa. J Nutr Sci Vitaminol (Tokyo) 51, 156-160.

7. Velazquez OC, Jabbar A, DeMatteo RP, et al. (1996) Butyrate inhibits seeding and growth of colorectal metastases to the liver in mice. Surgery 120, 440-447.

8. Guilloteau P, Zabielski R, David JC, et al. (2009) Sodiumbutyrate as a growth promoter in milk replacer formula for young calves. J Dairy Sci 92, 1038-1049.

9. Stark PL \& Lee A (1982) The bacterial colonization of the large bowel of pre-term low birth weight neonates. J Hyg (Lond) 89, 59-67.

10. Hold GL, Pryde SE, Russell VJ, et al. (2002) Assessment of microbial diversity in human colonic samples by $16 \mathrm{~S}$ rDNA sequence analysis. FEMS Microbiol Ecol 39, 33-39.

11. Duncan SH, Louis P \& Flint HJ (2007) Cultivable bacterial diversity from the human colon. Lett Appl Microbiol 44, $343-350$.

12. Alais C (1984) Science du Lait. Principes des Techniques Laitières (Science of Milk. Priniples of Dairy Technology). Paris: Société d'Edition et de Promotion Agro-Alimentaire, Industrielle et Commerciale.

13. Guilloteau P, Biernat M, Wolinski J, et al (2002) Gut regulatory peptides and hormones of the small intestine. In Biology of Intestine in Growing Animals, pp. 271-324 [R Zabielski, B Gregory and B Westrom, editors]. Amsterdam: Elsevier Science.

14. Krishnan S \& Ramakrishna BS (1998) Butyrate and glucose metabolism in isolated colonocytes in the developing rat colon. J Pediatr Gastroenterol Nutr 26, 432-436.

15. Ogawa K, Ben RA, Pons S, et al. (1992) Volatile fatty acids, lactic acid, and $\mathrm{pH}$ in the stools of breast-fed and bottle-fed infants. J Pediatr Gastroenterol Nutr 15, 248-252.

16. Edwards CA, Parrett AM, Balmer SE, et al. (1994) Faecal short chain fatty acids in breast-fed and formula-fed babies. Acta Paediatr 83, 459-462.

17. Li H, Myeroff L, Smiraglia D, et al. (2003) SLC5A8, a sodium transporter, is a tumor suppressor gene silenced by methylation in human colon aberrant crypt foci and cancers. Proc Natl Acad Sci U S A 100, 8412-8417. 
18. Midtvedt AC \& Midtvedt T (1992) Production of short chain fatty acids by the intestinal microflora during the first 2 years of human life. J Pediatr Gastroenterol Nutr 15, $395-403$.

19. van Der Wielen PW, Biesterveld S, Notermans S, et al. (2000) Role of volatile fatty acids in development of the cecal microflora in broiler chickens during growth. Appl Environ Microbiol 66, 2536-2540.

20. Elsden SR, Hichcock MWS, Marshall RA, et al. (1946) Volatile acid in the digesta of ruminants and other animals. J Exp Biol 22, 191-202.

21. McKay LF \& Eastwood MA (1983) The influence of dietary fibre on caecal metabolism in the rat. Br J Nutr 50, 679-684.

22. Hamer HM, Jonkers D, Venema K, et al. (2008) Review article: the role of butyrate on colonic function. Aliment Pharmacol Ther 27, 104-119.

23. Roberfroid MB (2005) Introducing inulin-type fructans. Br J Nutr 93, Suppl. 1, S13-S25.

24. Savage DC (1986) Gastrointestinal microflora in mammalian nutrition. Annu Rev Nutr 6, 155-178.

25. Miller TL \& Jenesel SE (1979) Enzymology of butyrate formation by Butyrivibrio fibrisolvens. J Bacteriol 138, 99-104.

26. Duncan SH, Barcenilla A, Stewart CS, et al. (2002) Acetate utilization and butyryl coenzyme A (CoA): acetate-CoA transferase in butyrate-producing bacteria from the human large intestine. Appl Environ Microbiol 68, 5186-5190.

27. Diez-Gonzalez F, Bond DR, Jennings E, et al. (1999) Alternative schemes of butyrate production in Butyrivibrio fibrisolvens and their relationship to acetate utilization, lactate production, and phylogeny. Arch Microbiol 171, 324-330.

28. Englyst HN, Kingman SM \& Cummings JH (1992) Classification and measurement of nutritionally important starch fractions. Eur J Clin Nutr 46, Suppl. 2, S33-S50.

29. Walker AW, Duncan SH, William Leitch EC, et al. (2005) $\mathrm{pH}$ and peptide supply can radically alter bacterial populations and short-chain fatty acid ratios within microbial communities from the human colon. Appl Environ Microbiol 71, 3692-3700.

30. Weaver GA, Krause JA, Miller TL, et al. (1992) Cornstarch fermentation by the colonic microbial community yields more butyrate than does cabbage fiber fermentation; cornstarch fermentation rates correlate negatively with methanogenesis. Am J Clin Nutr 55, 70-77.

31. Marsono Y, Illman RJ, Clarke JM, et al. (1993) Plasma lipids and large bowel volatile fatty acids in pigs fed on white rice, brown rice and rice bran. Br J Nutr 70, 503-513.

32. Topping DL, Illman RJ, Clarke JM, et al. (1993) Dietary fat and fiber alter large bowel and portal venous volatile fatty acids and plasma cholesterol but not biliary steroids in pigs. J Nutr 123, 133-143.

33. Gottschalk G (1979) Bacterial fermentations. In Bacterial Metabolism, pp. 167-224 [MP Starr, editor]. New York: Springer-Verlag.

34. Falony G, Vlachou A, Verbrugghe K, et al. (2006) Crossfeeding between Bifidobacterium longum BB536 and acetate-converting, butyrate-producing colon bacteria during growth on oligofructose. Appl Environ Microbiol 72, 7835-7841.

35. Duncan SH, Louis P \& Flint HJ (2004) Lactate-utilizing bacteria, isolated from human feces, that produce butyrate as a major fermentation product. Appl Environ Microbiol 70, 5810-5817.
36. Bird AR, Brown IL \& Topping DL (2000) Starches, resistant starches, the gut microflora and human health. Curr Issues Intest Microbiol 1, 25-37.

37. Brouns F, Kettlitz B \& Arrigoni E (2002) Resistant starch and 'the butyrate revolution'. Trends Food Sci Technol 13, 251-261.

38. Silvi S, Rumney CJ, Cresci A, et al. (1999) Resistant starch modifies gut microflora and microbial metabolism in human flora-associated rats inoculated with faeces from Italian and UK donors. J Appl Microbiol 86, 521-530.

39. Jacobasch G, Dongowski G, Schmiedl D, et al. (2006) Hydrothermal treatment of Novelose 330 results in high yield of resistant starch type 3 with beneficial prebiotic properties and decreased secondary bile acid formation in rats. Br J Nutr 95, 1063-1074.

40. Brouns F, Arrigoni E, Langkilde AM, et al. (2007) Physiological and metabolic properties of a digestionresistant maltodextrin, classified as type 3 retrograded resistant starch. J Agric Food Chem 55, 1574-1581.

41. Damian F, Van den Mooter G, Samyn C, et al. (1999) In vitro biodegradation study of acetyl and methyl inulins by Bifidobacteria and inulinase. Eur J Pharm Biopharm 47, $275-282$.

42. Weaver GA, Tangel CT, Krause JA, et al. (1997) Acarbose enhances human colonic butyrate production. J Nutr 127, $717-723$.

43. Le Blay G, Michel C, Blottière HM, et al. (1999) Enhancement of butyrate production in the rat caecocolonic tract by long-term ingestion of resistant potato starch. Br J Nutr 82, 419-426.

44. Le Blay G, Michel C, Blottière HM, et al. (1999) Prolonged intake of fructo-oligosaccharides induces a short-term elevation of lactic acid-producing bacteria and a persistent increase in cecal butyrate in rats. J Nutr 129, 2231-2235.

45. Linington M, Meyer J \& van der Walt J (1998) Ruminal VFA rates, whole body metabolite kinetics an blood hormones conentrations in sheep fed high- and low-fibre diets. S Afr J Anim Sci 28, 82.

46. Leng RA \& Leonard GJ (1965) Measurement of the rates of production of acetic, propionic and butyric acids in the rumen of sheep. Br J Nutr 19, 469-484.

47. Turnbaugh PJ \& Gordon JI (2009) The core gut microbiome, energy balance and obesity. J Physiol 587, 4153-4158.

48. Ley RE, Hamady M, Lozupone C, et al. (2008) Evolution of mammals and their gut microbes. Science 320, 1647-1651.

49. Eckburg PB, Bik EM, Bernstein CN, et al. (2005) Diversity of the human intestinal microbial flora. Science $\mathbf{3 0 8}$, 1635-1638.

50. Pryde SE, Richardson AJ, Stewart CS, et al. (1999) Molecular analysis of the microbial diversity present in the colonic wall, colonic lumen, and cecal lumen of a pig. Appl Environ Microbiol 65, 5372-5377.

51. Daly K, Stewart CS, Flint HJ, et al. (2001) Bacterial diversity within the equine large intestine as revealed by molecular analysis of cloned 16S rRNA genes. FEMS Microbiol Ecol 38, 141-151.

52. Apajalahti J, Kettunen A \& Graham H (2004) Characteristics of the gastrointestinal microbial communities, with special reference to the chicken. World Poult Sci J 60, 223-232.

53. Lu J, Idris U, Harmon B, et al. (2003) Diversity and succession of the intestinal bacterial community of the maturing broiler chicken. Appl Environ Microbiol 69, 6816-6824. 
54. Sonnenburg JL, Xu J, Leip DD, et al. (2005) Glycan foraging in vivo by an intestine-adapted bacterial symbiont. Science 307, 1955-1959.

55. Collins MD, Lawson PA, Willems A, et al. (1994) The phylogeny of the genus Clostridium: proposal of five new genera and eleven new species combinations. Int J Syst Bacteriol 44, 812-826.

56. Louis P \& Flint HJ (2009) Diversity, metabolism and microbial ecology of butyrate-producing bacteria from the human large intestine. FEMS Microbiol Lett 294, 1-8.

57. Aminov RI, Walker AW, Duncan SH, et al. (2006) Molecular diversity, cultivation, and improved detection by fluorescent in situ hybridization of a dominant group of human gut bacteria related to Roseburia spp. or Eubacterium rectale. Appl Environ Microbiol 72, 6371-6376.

58. Eeckhaut V, Van Immerseel F, Teirlynck E, et al. (2008) Butyricicoccus pullicaecorum gen. nov., sp. nov., an anaerobic, butyrate-producing bacterium isolated from the caecal content of a broiler chicken. Int J Syst Evol Microbiol 58, 2799-2802.

59. Eeckhaut V, Van Immerseel F, Pasmans F, et al. (2010) Anaerostipes butyraticus sp. nov., an anaerobic, butyrateproducing bacterium from Clostridium cluster XIVa isolated from broiler chicken caecal content, and emended description of the genus Anaerostipes. Int J Syst Evol Microbiol 60, 1108-1112.

60. Bryant MP (1986) Genus IV. Butyrivibrio Bryant and Small 1956, 18, emerd. Moore, Johnson and Holdeman 1976, 241. In Bergey's Manual of Systematic Bacteriology, 2nd ed., pp. 1376-1379 [PHA Sneath, NS Mair, ME Sharpe, et al., editors]. Baltimore: Williams and Wilkins.

61. Stewart CS, Flint HJ \& Bryant MP (1997) The rumen bacteria. In The Rumen Microbial Ecosystem, pp. 10-72 [PN Hobson and CS Stewart, editors]. London: Chapman and Hall.

62. Hespell RB (1992) The genera Butyrivibrio, Lachnospira, and Roseburia. In The Prokaryotes, 2nd ed., pp. 2022-2033 [A Balows, HG Truper, M Dworkin, et al., editors]. New York: Springer-Verlag Inc.

63. Sokol H, Pigneur B, Watterlot L, et al. (2008) Faecalibacterium prausnitzii is an anti-inflammatory commensal bacterium identified by gut microbiota analysis of Crohn disease patients. Proc Natl Acad Sci U S A 105, $16731-16736$.

64. Morrison DJ, Mackay WG, Edwards CA, et al. (2006) Butyrate production from oligofructose fermentation by the human faecal flora: what is the contribution of extracellular acetate and lactate? Br J Nutr 96, 570-577.

65. Ruppin H, Bar-Meir S, Soergel KH, et al. (1980) Absorption of short-chain fatty acids by the colon. Gastroenterology $\mathbf{7 8}$, $1500-1507$.

66. Schmitt MG Jr, Soergel KH, Wood CM, et al. (1977) Absorption of short-chain fatty acids from the human ileum. Am J Dig Dis 22, 340-347.

67. Gill RK, Saksena S, Alrefai WA, et al. (2005) Expression and membrane localization of MCT isoforms along the length of the human intestine. Am J Physiol Cell Physiol 289, C846-C852.

68. Ritzhaupt A, Wood IS, Ellis A, et al. (1998) Identification and characterization of a monocarboxylate transporter (MCT1) in pig and human colon: its potential to transport L-lactate as well as butyrate. $J$ Physiol 513, 719-732.

69. Ritzhaupt A, Ellis A, Hosie KB, et al. (1998) The characterization of butyrate transport across pig and human colonic luminal membrane. J Physiol 507, 819-830.
70. Ganapathy V, Thangaraju M, Gopal E, et al. (2008) Sodiumcoupled monocarboxylate transporters in normal tissues and in cancer. AAPS J 10, 193-199.

71. Tyagi S, Venugopalakrishnan J, Ramaswamy $\mathrm{K}$, et al. (2002) Mechanism of $n$-butyrate uptake in the human proximal colonic basolateral membranes. Am J Physiol Gastrointest Liver Physiol 282, G676-G682.

72. Aschenbach JR, Bilk S, Tadesse G, et al. (2009) Bicarbonate-dependent and bicarbonate-independent mechanisms contribute to nondiffusive uptake of acetate in the ruminal epithelium of sheep. Am J Physiol Gastrointest Liver Physiol 296, G1098-G1107.

73. Gupta N, Martin PM, Prasad PD, et al. (2006) SLC5A8 (SMCT1)-mediated transport of butyrate forms the basis for the tumor suppressive function of the transporter. Life Sci 78, 2419-2425.

74. Thibault R, Blachier F, Darcy-Vrillon B, et al. (2010) Butyrate utilization by the colonic mucosa in inflammatory bowel diseases: a transport deficiency. Inflamm Bowel Dis 16, 684-695.

75. Ganapathy V, Thangaraju M \& Prasad PD (2009) Nutrient transporters in cancer: relevance to Warburg hypothesis and beyond. Pharmacol Ther 121, 29-40.

76. Frank H, Groger N, Diener M, et al. (2008) Lactaturia and loss of sodium-dependent lactate uptake in the colon of SLC5A8-deficient mice. J Biol Chem 283, 24729-24737.

77. Tazoe H, Otomo Y, Kaji I, et al. (2008) Roles of short-chain fatty acids receptors, GPR41 and GPR43 on colonic functions. J Physiol Pharmacol 59, Suppl. 2, 251-262.

78. Tazoe H, Otomo Y, Karaki S, et al. (2009) Expression of short-chain fatty acid receptor GPR41 in the human colon. Biomed Res 30, 149-156.

79. Stoddart LA, Smith NJ \& Milligan G (2008) International Union of Pharmacology. LXXI. Free fatty acid receptors FFA1,-2, and-3: pharmacology and pathophysiological functions. Pharmacol Rev 60, 405-417.

80. Nilsson NE, Kotarsky K, Owman C, et al. (2003) Identification of a free fatty acid receptor, FFA2R, expressed on leukocytes and activated by short-chain fatty acids. Biochem Biophys Res Commun 303, 1047-1052.

81. Le Poul E, Loison C, Struyf S, et al. (2003) Functional characterization of human receptors for short chain fatty acids and their role in polymorphonuclear cell activation. J Biol Chem 278, 25481-25489.

82. Brown AJ, Goldsworthy SM, Barnes AA, et al. (2003) The Orphan G protein-coupled receptors GPR41 and GPR43 are activated by propionate and other short chain carboxylic acids. J Biol Chem 278, 11312-11319.

83. Maslowski KM, Vieira AT, Ng A, et al. (2009) Regulation of inflammatory responses by gut microbiota and chemoattractant receptor GPR43. Nature 461, 1282-1286.

84. Karaki S, Tazoe H, Hayashi H, et al. (2008) Expression of the short-chain fatty acid receptor, GPR43, in the human colon. J Mol Histol 39, 135-142.

85. Karaki S, Mitsui R, Hayashi H, et al. (2006) Short-chain fatty acid receptor, GPR 43, is expressed by enteroendocrine cells and mucosal mast cells in rat intestine. Cell Tissue Res 324, 353-360.

86. Karaki SI \& Kuwahara A (2010) Free fatty acid receptors and their physiological roles in the colon. Medycyna Wet 66 , 147-155.

87. Moreau NM, Champ MM, Goupry SM, et al. (2004) Resistant starch modulates in vivo colonic butyrate uptake and its oxidation in rats with dextran sulfate sodiuminduced colitis. J Nutr 134, 493-500.

88. Sakata T \& Von Engelhardt W (1983) Stimulatory effect of short chain fatty acids on the epithelial cell proliferation in 
rat large intestine. Comp Biochem Physiol A Comp Physiol 74, 459-462.

89. Del Castillo JR, Muniz R, Sulbaran-Carrasco MC, et al (1994) Cellular metabolism of colonocytes. In Short Chain Fatty Acids, pp. 180-194 [HJ Binder, J Cummings and KH Soergel, editors]. Lancaster, UK: Kluwer Academic Publishers.

90. Roediger WE (1994) Famine, fiber, fatty acids, and failed colonic absorption: does fiber fermentation ameliorate diarrhea? JPEN J Parenter Enteral Nutr 18, 4-8.

91. Martin LJ, Dumon HJ \& Champ MM (1998) Production of short chain fatty acids from resistant starch in a pig model. J Sci Food Agri 77, 71-80.

92. Moreau NM, Martin LJ, Toquet CS, et al. (2003) Restoration of the integrity of rat caeco-colonic mucosa by resistant starch, but not by fructo-oligosaccharides, in dextran sulfate sodium-induced experimental colitis. Br J Nutr 90, 75-85.

93. Kristensen NB \& Harmon DL (2004) Effect of increasing ruminal butyrate absorption on splanchnic metabolism of volatile fatty acids absorbed from the washed reticulorumen of steers. J Anim Sci 82, 3549-3559.

94. Manzanilla EG, Nofrarias M, Anguita M, et al. (2006) Effects of butyrate, avilamycin, and a plant extract combination on the intestinal equilibrium of early-weaned pigs. J Anim Sci 84, 2743-2751.

95. Gao Z, Yin J, Zhang J, et al. (2009) Butyrate improves insulin sensitivity and increases energy expenditure in mice. Diabetes 58, 1509-1517.

96. Topping DL \& Clifton PM (2001) Short-chain fatty acids and human colonic function: roles of resistant starch and nonstarch polysaccharides. Physiol Rev 81, 1031-1064.

97. Egorin MJ, Yuan ZM, Sentz DL, et al. (1999) Plasma pharmacokinetics of butyrate after intravenous administration of sodium butyrate or oral administration of tributyrin or sodium butyrate to mice and rats. Cancer Chemother Pharmacol 43, 445-453.

98. Martin LJ, Dumon HJ, Lecannu G, et al. (2000) Potato and high-amylose maize starches are not equivalent producers of butyrate for the colonic mucosa. Br J Nutr 84, 689-696.

99. Bach Knudsen KE, Serena A, Kjaer AK, et al. (2005) Rye bread enhances the production and plasma concentration of butyrate but not the plasma concentrations of glucose and insulin in pigs. $J$ Nutr 135, 1696-1704.

100. Bloemen JG, Venema K, van de Poll MC, et al. (2009) Short chain fatty acids exchange across the gut and liver in humans measured at surgery. Clin Nutr 28, 657-661.

101. Beauvieux MC, Tissier P, Gin H, et al. (2001) Butyrate impairs energy metabolism in isolated perfused liver of fed rats. J Nutr 131, 1986-1992.

102. Gallis JL, Tissier P, Gin H, et al. (2007) Decrease in oxidative phosphorylation yield in presence of butyrate in perfused liver isolated from fed rats. BMC Physiol 7, 8 .

103. Beauvieux MC, Roumes H, Robert N, et al. (2008) Butyrate ingestion improves hepatic glycogen storage in the re-fed rat. BMC Physiol 8, 19.

104. Shin HJ, Anzai N, Enomoto A, et al. (2007) Novel liverspecific organic anion transporter OAT7 that operates the exchange of sulfate conjugates for short chain fatty acid butyrate. Hepatology 45, 1046-1055.

105. Mariadason JM, Kilias D, Catto-Smith A, et al. (1999) Effect of butyrate on paracellular permeability in rat distal colonic mucosa ex vivo. J Gastroenterol Hepatol 14, 873-879.

106. Cook SI \& Sellin JH (1998) Review article: short chain fatty acids in health and disease. Aliment Pharmacol Ther $\mathbf{1 2}$ 499-507.
107. Roediger WE (1980) The colonic epithelium in ulcerative colitis: an energy-deficiency disease? Lancet ii, 712-715.

108. Roediger WE (1980) Role of anaerobic bacteria in the metabolic welfare of the colonic mucosa in man. Gut 21, 793-798.

109. Jacobasch G, Schmiedl D, Kruschewski M, et al. (1999) Dietary resistant starch and chronic inflammatory bowel diseases. Int J Colorectal Dis 14, 201-211.

110. Salminen A, Tapiola T, Korhonen P, et al. (1998) Neuronal apoptosis induced by histone deacetylase inhibitors. Brain Res Mol Brain Res 61, 203-206.

111. Le Gall M, Gallois M, Sève B, et al. (2009) Comparative effect of orally administered sodium butyrate before or after weaning on growth and several indices of gastrointestinal biology of piglets. Br J Nutr 102, 1285-1296.

112. Kotunia A, Wolinski J, Laubitz D, et al. (2004) Effect of sodium butyrate on the small intestine development in neonatal piglets fed [correction of feed] by artificial sow. J Physiol Pharmacol 55, Suppl. 2, 59-68.

113. Bartholome AL, Albin DM, Baker DH, et al. (2004) Supplementation of total parenteral nutrition with butyrate acutely increases structural aspects of intestinal adaptation after an $80 \%$ jejunoileal resection in neonatal piglets. JPEN J Parenter Enteral Nutr 28, 210-222.

114. Frankel W, Lew J, Su B, et al. (1994) Butyrate increases colonocyte protein synthesis in ulcerative colitis. J Surg Res 57, 210-214

115. Sakata T (1987) Stimulatory effect of short-chain fatty acids on epithelial cell proliferation in the rat intestine: a possible explanation for trophic effects of fermentable fibre, gut microbes and luminal trophic factors. Br J Nutr 58, 95-103.

116. Sengupta S, Muir JG \& Gibson PR (2006) Does butyrate protect from colorectal cancer? J Gastroenterol Hepatol 21, 209-218.

117. Wang JF, Chen YX, Xang ZX, et al. (2005) Effect of sodium butyrate on the structure of the small intestine mucous epithelium of weaning piglets. Chin J Vet Sci Technol 35, 298-301.

118. Lacorn M, Goerke M \& Claus R (2010) Inulin-coated butyrate increases ileal MCT1 expression and affects mucosal morphology in the porcine ileum by reduced apoptosis. J Anim Physiol Anim Nutr (Berl) 94, 670-676.

119. Nofrarias M, Martinez-Puig D, Pujols J, et al. (2007) Longterm intake of resistant starch improves colonic mucosal integrity and reduces gut apoptosis and blood immune cells. Nutrition 23, 861-870.

120. Le Leu RK, Brown IL, Hu Y, et al. (2003) Effect of resistant starch on genotoxin-induced apoptosis, colonic epithelium, and lumenal contents in rats. Carcinogenesis 24, $1347-1352$

121. Mentschel J \& Claus R (2003) Increased butyrate formation in the pig colon by feeding raw potato starch leads to a reduction of colonocyte apoptosis and a shift to the stem cell compartment. Metabolism 52, 1400-1405.

122. Luciano L, Groos S, Busche R, et al. (2002) Massive apoptosis of colonocytes induced by butyrate deprivation overloads resident macrophages and promotes the recruitment of circulating monocytes. Cell Tissue Res $\mathbf{3 0 9}$, 393-407.

123. Blottière HM, Buecher B, Galmiche JP, et al. (2003) Molecular analysis of the effect of short-chain fatty acids on intestinal cell proliferation. Proc Nutr Soc 62, 101-106.

124. Bailón E, Cueto-Sola M, Utrilla P, et al. (2010) Butyrate in vitro immune-modulatory effects might be mediated through a proliferation-related induction of apoptosis. Immunobiology (epublication ahead of print version 13 January 2010). 
125. Zeng H \& Briske-Anderson M (2005) Prolonged butyrate treatment inhibits the migration and invasion potential of HT1080 tumor cells. J Nutr 135, 291-295.

126. Bordonaro M, Lazarova DL \& Sartorelli AC (2007) The activation of $\beta$-catenin by Wnt signaling mediates the effects of histone deacetylase inhibitors. Exp Cell Res 313, $1652-1666$.

127. Zhang Y, Zhou L, Bao YL, et al. (2010) Butyrate induces cell apoptosis through activation of JNK MAP kinase pathway in human colon cancer RKO cells. Chem Biol Interact 185, 174-181.

128. Aoyama M, Kotani J \& Usami M (2010) Butyrate and propionate induced activated or non-activated neutrophil apoptosis via HDAC inhibitor activity but without activating GPR-41/GPR-43 pathways. Nutrition 26, 653-661.

129. Le NH, Franken P \& Fodde R (2008) Tumour-stroma interactions in colorectal cancer: converging on $\beta$-catenin activation and cancer stemness. Br J Cancer 98, 1886-1893.

130. Bordonaro M, Lazarova DL \& Sartorelli AC (2008) Butyrate and Wnt signaling: a possible solution to the puzzle of dietary fiber and colon cancer risk? Cell Cycle 7, 1178-1183.

131. Gorka P, Kowalski ZM, Pietrzak P, et al. (2009) Effect of sodium butyrate supplementation in milk replacer and starter diet on rumen development in calves. J Physiol Pharmacol 60, Suppl. 3, 47-53.

132. Claus R, Gunthner D \& Letzguss H (2007) Effects of feeding fat-coated butyrate on mucosal morphology and function in the small intestine of the pig. J Anim Physiol Anim Nutr (Berl) 91, 312-318.

133. Pouillart PR (1998) Role of butyric acid and its derivatives in the treatment of colorectal cancer and hemoglobinopathies. Life Sci 63, 1739-1760.

134. Gauthier R (2002) The mode of action of acidifiers and the interest they generate in the growing-finishing phase. In Current Developments in Pig Production, p. 16 [French Association of Swine Practitioners, editors]. Maisons-Alfort, France: French Association of Swine Practitioners.

135. Scheppach W \& Weiler F (2004) The butyrate story: old wine in new bottles? Curr Opin Clin Nutr Metab Care 7, 563-567.

136. Franco LD, Fondevila M, Lobera MB, et al. (2005) Effect of combinations of organic acids in weaned pig diets on microbial species of digestive tract contents and their response on digestibility. J Anim Physiol Anim Nutr (Berl) 89, 88-93.

137. Mroz Z (2005) Organic acids as potential alternative to antibiotic growth promoters for pigs. Adv Pork Prod 16, 169-182.

138. Mazzoni M, Le Gall M, De Filippi S, et al. (2008) Supplemental sodium butyrate stimulates different gastric cells in weaned pigs. J Nutr 138, 1426-1431.

139. Guilloteau P, Romé L, Le Normand G, et al. (2004) Is Nabutyrate a growth factor in preruminant calf? Preliminary results. J Anim Sci 13, 393-396.

140. Galfi P \& Bokori J (1990) Feeding trial in pigs with a diet containing sodium $n$-butyrate. Acta Vet Hung 38, 3-17.

141. Galfi P, Gabel G \& Martens H (1993) Influences of extracellular matrix components on the growth and differentiation of ruminal epithelial cells in primary culture. Res Vet Sci 54, 102-109.

142. Biagi G, Piva A, Moschini M, et al. (2007) Performance, intestinal microflora, and wall morphology of weanling pigs fed sodium butyrate. J Anim Sci 85, 1184-1191.

143. Piva A, Pizzamiglio V, Morlacchini M, et al. (2007) Lipid microencapsulation allows slow release of organic acids and natural identical flavors along the swine intestine. J Anim Sci 85, 486-493.

144. Guilloteau P, Toullec R, Patureau-Mirand P, et al. (1981) Importance of the abomasum in digestion in the preruminant calf. Reprod Nutr Dev 21, 885-899.

145. Zabielski R, Dardillat C, Le Huerou-Luron I, et al. (1998) Periodic fluctuations of gut regulatory peptides in phase with the duodenal migrating myoelectric complex in preruminant calves: effect of different sources of dietary protein. Br J Nutr 79, 287-296.

146. Guilloteau P, Savary G, Jaguelin-Peyrault Y, et al. (2010) Dietary sodium-butyrate supplementation increases digestibility and pancreatic secretion in young milk fed calves. $J$ Dairy Sci (In the Press).

147. Pietrzak P, Kotunia A, Gorka P, et al. (2008) Does dietary sodium butyrate stimulate pancreas growth in formula fed calves? Pancreatology 8, 308

148. Pietrzak P, Kotunia A, Wrzesinska J, et al. (2008) Dietary sodium butyrate stimulates rebuilding of small intestine epithelium in neonatal calves. Folia Histochem Cytobiol 46, $\mathrm{s} 65$.

149. Sileikiene V, Mosenthin R, Tafaj M, et al. (2005) Effect of short chain fatty acids infused intraileally on interdigestive exocrine pancreatic secretions in growing pigs. J Anim Physiol Anim Nutr (Berl) 89, 253-259.

150. Guilloteau P, Toullec R, Sauvant D, et al. (1979) Utilisation des protéines par le veau préruminant à l'engrais. VIIInfluence du remplacement des protéines du lait par celles du soja ou de la févérole sur l'évacuation gastrique (Use of proteins by the preruminant calf for fattening. VII- Influence of replacement of milk proteins by those of soyabean or faba bean on gastric emptying). Ann Zootech 28, 1-17.

151. Guilloteau P \& Zabielski R (2005) Digestive secretions in preruminant and ruminant calves and some aspects of their regulation. In Calf and Heifer Rearing, pp. 159-189 [PC Garnsworthy, editor]. Nottingham, UK: Nottingham University Press.

152. Demol P \& Sarles H (1978) Action of fatty acids on the exocrine pancreatic secretion of the conscious rat: further evidence for a protein pancreatic inhibitory factor. $J$ Physiol 275, 27-37.

153. Harada E \& Kato S (1983) Effect of short-chain fatty acids on the secretory response of the ovine exocrine pancreas. Am J Physiol 244, G284-G290.

154. Harada E (1985) Comparison of pancreatic digestive enzyme secretion induced by volatile fatty acids in mice, Japanese field voles and goats. Comp Biochem Physiol A Comp Physiol 81, 539-543.

155. Kato S, Asakawa N, Mineo H, et al. (1989) Effect of shortchain fatty acids on pancreatic exocrine secretion in calves aged 2 weeks and 13 weeks. Nippon Juigaku Zasshi 51, 1123-1127.

156. Katoh K \& Yajima T (1989) Effects of butyric acid and analogues on amylase release from pancreatic segments of sheep and goats. Pflugers Arch 413, 256-260.

157. Claus R, Losel D, Lacorn M, et al. (2003) Effects of butyrate on apoptosis in the pig colon and its consequences for skatole formation and tissue accumulation. J Anim Sci 81, 239-248.

158. Weber TE \& Kerr BJ (2006) Butyrate differentially regulates cytokines and proliferation in porcine peripheral blood mononuclear cells. Vet Immunol Immunopathol 113, 139-147.

159. Andoh A, Bamba T \& Sasaki M (1999) Physiological and anti-inflammatory roles of dietary fiber and butyrate in intestinal functions. JPEN $J$ Parenter Enteral Nutr 23, S70-S73. 
160. Segain JP, Raingeard de la Blétière D, Bourreille A, et al. (2000) Butyrate inhibits inflammatory responses through NFKB inhibition: implications for Crohn's disease. Gut 47, $397-403$

161. Venkatraman A, Ramakrishna BS, Shaji RV, et al. (2003) Amelioration of dextran sulfate colitis by butyrate: role of heat shock protein 70 and NF-кB. Am J Physiol Gastrointest Liver Physiol 285, G177-G184.

162. Jiang Q, Elson-Schwab I, Courtemanche C, et al. (2000) $\gamma$-Tocopherol and its major metabolite, in contrast to $\alpha$-tocopherol, inhibit cyclooxygenase activity in macrophages and epithelial cells. Proc Natl Acad Sci U S A 97, 11494-11499.

163. Pirman T, Ribeyre MC, Mosoni L, et al. (2007) Dietary pectin stimulates protein metabolism in the digestive tract. Nutrition 23, 69-75.

164. Barcelo A, Claustre J, Moro F, et al. (2000) Mucin secretion is modulated by luminal factors in the isolated vascularly perfused rat colon. Gut 46, 218-224.

165. Ewing W \& Cole DJA (1994) The Living Gut. An Introduction to Micro-Organisms in Nutrition. Dungannon, UK: Context.

166. Castillo M, Martin-Orue SM, Roca M, et al. (2006) The response of gastrointestinal microbiota to avilamycin, butyrate, and plant extracts in early-weaned pigs. J Anim Sci 84, 2725-2734.

167. Van Immerseel F, Fievez V, De Buck J, et al. (2004) Microencapsulated short-chain fatty acids in feed modify colonization and invasion early after infection with Salmonella enteritidis in young chickens. Poult Sci $\mathbf{8 3}$, 69-74.

168. Roediger WE (1990) The starved colon - diminished mucosal nutrition, diminished absorption, and colitis. Dis Colon Rectum 33, 858-862.

169. Ahmad MS, Krishnan S, Ramakrishna BS, et al. (2000) Butyrate and glucose metabolism by colonocytes in experimental colitis in mice. Gut 46, 493-499.

170. Luhrs H, Gerke T, Muller JG, et al. (2002) Butyrate inhibits $\mathrm{NF}-\kappa \mathrm{B}$ activation in lamina propria macrophages of patients with ulcerative colitis. Scand J Gastroenterol 37, 458-466.

171. Okamoto T, Sasaki M, Tsujikawa T, et al. (2000) Preventive efficacy of butyrate enemas and oral administration of Clostridium butyricum M588 in dextran sodium sulfateinduced colitis in rats. J Gastroenterol 35, 341-346.

172. Kinoshita M, Suzuki Y \& Saito Y (2002) Butyrate reduces colonic paracellular permeability by enhancing PPAR $\gamma$ activation. Biochem Biophys Res Commun 293, 827-831.

173. Gaudier E, Jarry A, Blottière HM, et al. (2004) Butyrate specifically modulates MUC gene expression in intestinal epithelial goblet cells deprived of glucose. Am J Physiol Gastrointest Liver Physiol 287, G1168-G1174.

174. Peng L, Li ZR, Green RS, et al. (2009) Butyrate enhances the intestinal barrier by facilitating tight junction assembly via activation of AMP-activated protein kinase in Caco-2 cell monolayers. J Nutr 139, 1619-1625.

175. Ohata A, Usami M \& Miyoshi M (2005) Short-chain fatty acids alter tight junction permeability in intestinal monolayer cells via lipoxygenase activation. Nutrition $\mathbf{2 1}$, $838-847$.

176. Mangian HF \& Tappenden KA (2009) Butyrate increases GLUT2 mRNA abundance by initiating transcription in Caco2-BBe cells. JPEN J Parenter Enteral Nutr 33, 607-617.

177. Yazbeck R, Howarth GS \& Abbott CA (2009) Growth factor based therapies and intestinal disease: is glucagon-like peptide-2 the new way forward? Cytokine Growth Factor Rev 20, 175-184.
178. Mentschel J, Leiser R, Mulling C, et al. (2001) Butyric acid stimulates rumen mucosa development in the calf mainly by a reduction of apoptosis. Arch Tierernahr 55, 85-102.

179. Guilloteau P, Le Meuth-Metzinger V, Morisset J, et al. (2006) Gastrin, cholecystokinin and gastrointestinal tract functions in mammals. Nutr Res Rev 19, 254-283.

180. Simon B, Merchant JL, Eissele R, et al. (1997) Transient transcriptional activation of gastrin during sodium butyrateinduced differentiation of islet cells. Regul Pept 70, $143-148$.

181. Burrin DG, Guan X, Stoll B, et al. (2003) Glucagon-like peptide 2: a key link between nutrition and intestinal adaptation in neonates? J Nutr 133, 3712-3716.

182. Burrin DG, Stoll B, Guan X, et al. (2005) Glucagon-like peptide 2 dose-dependently activates intestinal cell survival and proliferation in neonatal piglets. Endocrinology 146, 22-32.

183. Tsubaki J, Choi WK, Ingermann AR, et al. (2001) Effects of sodium butyrate on expression of members of the IGFbinding protein superfamily in human mammary epithelial cells. J Endocrinol 169, 97-110.

184. Weickert MO \& Pfeiffer AF (2008) Metabolic effects of dietary fiber consumption and prevention of diabetes. $J$ Nutr 138, 439-442.

185. Freeland KR, Wilson C \& Wolever TM (2010) Adaptation of colonic fermentation and glucagon-like peptide-1 secretion with increased wheat fibre intake for 1 year in hyperinsulinaemic human subjects. Br J Nutr 103, 82-90.

186. Kyner D, Zabos P, Christman J, et al. (1976) Effect of sodium butyrate on lymphocyte activation. J Exp Med 144, 1674-1678.

187. Cavaglieri CR, Nishiyama A, Fernandes LC, et al. (2003) Differential effects of short-chain fatty acids on proliferation and production of pro- and anti-inflammatory cytokines by cultured lymphocytes. Life Sci 73, 1683-1690.

188. Jackson SK, DeLoose A \& Gilbert KM (2002) The ability of antigen, but not interleukin-2, to promote $n$-butyrateinduced $\mathrm{T}$ helper 1 cell anergy is associated with increased expression and altered association patterns of cyclindependent kinase inhibitors. Immunology 106, 486-495.

189. Nancey S, Bienvenu J, Coffin B, et al. (2002) Butyrate strongly inhibits in vitro stimulated release of cytokines in blood. Dig Dis Sci 47, 921-928.

190. Saemann MD, Bohmig GA, Osterreicher CH, et al. (2000) Anti-inflammatory effects of sodium butyrate on human monocytes: potent inhibition of IL-12 and up-regulation of IL-10 production. FASEB J 14, 2380-2382.

191. Gibson P \& Rosella O (1995) Interleukin 8 secretion by colonic crypt cells in vitro: response to injury suppressed by butyrate and enhanced in inflammatory bowel disease. Gut 37, 536-543.

192. Narberhaus F (2002) $\alpha$-Crystallin-type heat shock proteins: socializing minichaperones in the context of a multichaperone network. Microbiol Mol Biol Rev 66, 64-93.

193. Sikora A \& Grzesiuk E (2007) Heat shock response in gastrointestinal tract. J Physiol Pharmacol 58, Suppl 3, 43-62.

194. Ren H, Musch MW, Kojima K, et al. (2001) Short-chain fatty acids induce intestinal epithelial heat shock protein 25 expression in rats and IEC 18 cells. Gastroenterology $\mathbf{1 2 1}$, 631-639.

195. Arvans DL, Vavricka SR, Ren H, et al. (2005) Luminal bacterial flora determines physiological expression of intestinal epithelial cytoprotective heat shock proteins 25 and 72. Am J Physiol Gastrointest Liver Physiol 288, G696-G704. 
196. Ropeleski MJ, Tang J, Walsh-Reitz MM, et al. (2003) Interleukin-11-induced heat shock protein 25 confers intestinal epithelial-specific cytoprotection from oxidant stress. Gastroenterology 124, 1358-1368.

197. Musch MW, Ciancio MJ, Sarge K, et al. (1996) Induction of heat shock protein 70 protects intestinal epithelial IEC-18 cells from oxidant and thermal injury. Am J Physiol 270, C429-C436.

198. Shen L, Keenan MJ, Martin RJ, et al. (2009) Dietary resistant starch increases hypothalamic POMC expression in rats. Obesity (Silver Spring) 17, 40-45.

199. Zhou J, Hegsted M, McCutcheon KL, et al. (2006) Peptide YY and proglucagon mRNA expression patterns and regulation in the gut. Obesity (Silver Spring) 14, 683-689.

200. Yonekura S, Senoo T, Kobayashi Y, et al. (2003) Effects of acetate and butyrate on the expression of leptin and shortform leptin receptor in bovine and rat anterior pituitary cells. Gen Comp Endocrinol 133, 165-172.

201. Roessner A, Kuester D, Malfertheiner P, et al. (2008) Oxidative stress in ulcerative colitis-associated carcinogenesis. Pathol Res Pract 204, 511-524.

202. Rosignoli P, Fabiani R, De Bartolomeo A, et al. (2001) Protective activity of butyrate on hydrogen peroxideinduced DNA damage in isolated human colonocytes and HT29 tumour cells. Carcinogenesis 22, 1675-1680.

203. Sauer J, Richter KK \& Pool-Zobel BL (2007) Physiological concentrations of butyrate favorably modulate genes of oxidative and metabolic stress in primary human colon cells. J Nutr Biochem 18, 736-745.

204. Hamer HM, Jonkers DM, Bast A, et al. (2009) Butyrate modulates oxidative stress in the colonic mucosa of healthy humans. Clin Nutr 28, 88-93.

205. Ricke SC (2003) The gastrointestinal tract ecology of Salmonella enteritidis colonization in molting hens. Poult Sci 82, 1003-1007.
206. Davidson PM (2001) Chemical preservatives and natural antimicrobial compounds. In Foods Microbiology Fundamentals and Frontiers, pp. 593-627 [MP Doyle, LR Beuchat and TJ Montville, editors]. Washington, DC: American Society for Microbiology.

207. Russell JB \& Diez-Gonzalez F (1998) The effects of fermentation acids on bacterial growth. Adv Microb Physiol 39, 205-234.

208. Cherrington CA, Hinton M, Mead GC, et al. (1991) Organic acids: chemistry, antibacterial activity and practical applications. Adv Microb Physiol 32, 87-108.

209. Desmidt M, Ducatelle R \& Haesebrouck F (1997) Pathogenesis of Salmonella enteritidis phage type four after experimental infection of young chickens. Vet Microbiol 56, 99-109.

210. Van Immerseel F, De Buck J, De Smet I, et al. (2004) Interactions of butyric acid- and acetic acid-treated Salmonella with chicken primary cecal epithelial cells in vitro. Avian Dis 48, 384-391.

211. Gantois I, Ducatelle R, Pasmans F, et al. (2006) Butyrate specifically down-regulates Salmonella pathogenicity island 1 gene expression. Appl Environ Microbiol 72, 946-949.

212. Nakanishi N, Tashiro K, Kuhara S, et al. (2009) Regulation of virulence by butyrate sensing in enterohaemorrhagic Escherichia coli. Microbiology 155, 521-530.

213. Timbermont L, Lanckriet A, Dewulf J, et al. (2010) Control of Clostridium perfringens-induced necrotic enteritis in broilers by target-released butyric acid, fatty acids and essential oils. Avian Pathol 39, 117-121.

214. Van Deun K, Pasmans F, Van Immerseel F, et al. (2008) Butyrate protects Caco-2 cells from Campylobacter jejuni invasion and translocation. Br J Nutr 100, 480-484.

215. Siavoshian S, Blottière HM, Le Foll E, et al. (1997) Comparison of the effect of different short chain fatty acids on the growth and differentiation of human colonic carcinoma cell lines in vitro. Cell Biol Int 21, 281-287. 